'llu. Revista de Ciencias de las Religiones

ISSN: $1135-4712$

http://dx.doi.org/10.5209/ILUR.57410

\title{
Los principales referentes intelectuales de Ángel Álvarez de Miranda, historiador de las religiones ${ }^{1}$
}

\author{
Francisco Díez de Velasco²
}

Recibido: 4 de abril de 2017 / Aceptado: 18 de julio de 2017

Resumen. Revisión de los referentes intelectuales de Ángel Álvarez de Miranda, que fue catedrático de Historia de las Religiones en la Universidad de Madrid desde 1954 hasta su muerte en 1957. Se repasan en especial las figuras de Mircea Eliade y Raffaele Pettazzoni, pero también se revisa el uso que hace de las obras de Santiago Montero Díaz, Pedro Laín Entralgo, Marcelino Menéndez Pelayo, José Ortega y Gasset, Karl Kerenyi, Angelo Brelich, Xavier Zubiri, José Luis López Aranguren, Julio Caro Baroja, Wilhelm Schmidt y Gerardus van der Leeuw.

Palabras clave: Ángel Álvarez de Miranda; historia de las religiones; Mircea Eliade; Raffaele Pettazzoni; Santiago Montero.

\section{[en] The main intellectual referents of Ángel Álvarez de Miranda, historian of religions}

\begin{abstract}
Revision of the main intellectual referents of Ángel Álvarez de Miranda who was professor of History of Religions at the University of Madrid from 1954 until his death in 1957. A more detailed study is made of Mircea Eliade and Raffaele Pettazzoni, but also are revised Santiago Montero Díaz, Pedro Laín Entralgo, Marcelino Menéndez Pelayo, José Ortega y Gasset, Karl Kerenyi, Angelo Brelich, Xavier Zubiri, José Luis López Aranguren, Julio Caro Baroja, Wilhelm Schmidt and Gerardus van der Leeuw.
\end{abstract}

Keywords: Ángel Álvarez de Miranda; history of religions; Mircea Eliade; Raffaele Pettazzoni; Santiago Montero.

Sumario. 1. La historia de las religiones en España y la figura de Álvarez de Miranda. 2. Mircea Eliade como principal referente intelectual. 3. El magisterio de Raffaele Pettazzoni. 4. Otros referentes intelectuales. 5. Bibliografía.

Cómo citar: Díez de Velasco, F. (2017), Los principales referentes intelectuales de Ángel Álvarez de Miranda, historiador de las religiones, en 'Ilu. Revista de Ciencias de las Religiones 22, 97-144.

1 Este trabajo se inserta en el contexto del proyecto de investigación «Bases teóricas y metodológicas para el estudio de la diversidad religiosa y las minorías religiosas en España» (HAR2016-75173-P) del Ministerio de Economía y Competitividad de España, 2017-2020. Es una reelaboración de la ponencia presentada en la Jornada Académica «La Historia de las Religiones en España: la influencia de la escuela italiana. Homenaje a Ángel Álvarez de Miranda», organizada por el Instituto de Ciencias de las Religiones de la Universidad Complutense de Madrid el 14 de noviembre de 2016.

2 Universidad de La Laguna (España). ORCID: 0000-0002-9913-4580.

E-mail: fradive@ull.edu.es 


\section{La historia de las religiones en España y la figura de Álvarez de Miranda}

La Historia de las Religiones no tuvo en España, antes de Ángel Álvarez de Miranda, verdaderos cultivadores ${ }^{3}$. Por tanto no se contaba con ejemplos destacados donde hallar referentes intelectuales españoles de la disciplina, y aunque los temas religiosos desde luego interesaban y habían interesado a muy diferentes pensadores del país, solían deambular lejos de la perspectiva enfocada en la pluralidad que caracteriza a la Historia de las Religiones y solían centrarse en la singularidad católica (pro o contra).

Álvarez de Miranda, en tanto que historiador de las religiones, tuvo que formarse fuera de España y lo hizo en Italia. Vivió en Roma entre los años 1948 y 1954 desempeñando el puesto de Director del Instituto Español de Lengua y Literatura ${ }^{4}$ y fue allí donde se especializó y se introdujo en el contexto intelectual internacional de la disciplina. Su maestro fue Raffaele Pettazzoni que desde diciembre de 1950, y tras la muerte de Gerardus van der Leeuw, era presidente de la recién fundada (en septiembre) International Association for the Study of the History of Religions y estaba en contacto con los principales especialistas mundiales en la materia, que eran mayoritariamente europeos. Álvarez de Miranda conoció y asimiló la producción científica de estos autores tanto por su relación con el propio Pettazzoni y su participación en los seminarios y actividades que promovía en la Universidad de Roma y en la Società Italiana di Storia delle Religioni (puesta en marcha en 1951), como por las lecturas realizadas en las bibliotecas especializadas romanas (en especial la de la Universidad de Roma pero también la de la Universidad Gregoriana en la que siguió algunos cursos) y en la nutrida biblioteca personal sobre el tema que fue adquiriendo y que fue legada a la Biblioteca de la Facultad de Geografía e Historia de la Universidad Complutense de Madrid donde puede consultarse ${ }^{5}$. Lógicamente, esperaríamos que sus referentes intelectuales principales los hallásemos en ese horizonte bibliográfico y científico deslumbrante frente a lo poco que podía ofrecer su patria de origen. De hecho cabe la posibilidad de que hubiera pensado en algún momento en hacer carrera como historiador de las religiones fuera de España ${ }^{6}$, aunque desde 1951 en que es nombrado Ministro de Educación Nacional Joaquín Ruiz Giménez, a cuyo grupo tanto ideológico (en la línea de una incipiente democracia cristiana ${ }^{7}$ ) como de amigos pertenecía, comienza a consolidarse la opción de su vuelta a la uni-

3 Hubo algunos intentos infructuosos; el más cercano al éxito es el que promovió Antonio López Carballeira ante las autoridades del Ministerio de Educación durante la Segunda República, véase Díez de Velasco 2017a, 230-232.

$4 \quad$ Véase el detallado repaso al trabajo de su padre en el Instituto Español de Lengua y Literatura en Roma que realiza Pedro Álvarez de Miranda (Díez de Velasco/Álvarez de Miranda 2010, 555-562).

5 Sus herederos la donaron en 1987 (véase: Sin autor 1987).

6 Parece exponer esa perspectiva en una carta a Santiago Montero fechada el 23 de marzo de 1953: «Por lo demás, cuando hace ya casi cinco años, decidí consagrarme de lleno a la Historia de las Religiones, lo hice consciente de que ese no era un camino para llegar a la Universidad-por lo menos a la española-y no por eso estuve ya desde entonces menos decidido a hacer de esos estudios el eje de mi vida» (recogida en Díez de Velasco 2007a, 62, se conserva en el archivo de los herederos de Santiago Montero Díaz a quienes agradezco el acceso a la correspondencia con Álvarez de Miranda que consta de 14 cartas, del mismo modo los herederos de Álvarez de Miranda conservan 8 cartas de Santiago Montero cuyo acceso les agradezco).

7 Muñoz Soro 2006, 266; las circunstancias de su relación con Ruiz-Giménez se repasan en Díez de Velasco 2015, 12, incluida la fraternidad que les llevó a asistir ambos en la Semana Santa de 1948 a unos ejercicios espirituales como cuenta Castro en sus memorias (s/f. 133-134). Su mutua amistad quedó patente en el prólogo que redactó el exministro para el primer volumen del póstumo Obras (Ruíz-Giménez 1959). 
versidad española y en una catedra perfilada como de Historia de las Religiones ${ }^{8}$. Y es que Álvarez de Miranda había sido un muy destacado alumno en la Facultad de Filosofía de la Universidad Central de Madrid en la primera promoción tras el final de la Guerra Civil (había incluso conseguido el premio extraordinario de licenciatura en $1943^{9}$ ). Ya había publicado diversos artículos, prólogos, notas, reseñas, ediciones y traducciones (en algún caso tratando temas de carácter religioso ${ }^{10}$ ), y hasta había avanzado un libro sobre la cultura hispanoamericana ${ }^{11}$, antes de su estancia italiana. También había sido uno de los fundadores de la revista Alférez, en la que contribuyó con una decena de artículos, había publicado en la revista Cisneros y fue colaborador de Pedro Laín Entralgo, con quien le unía una larga amistad ${ }^{12}$, en la fundación y primeros años de la revista Cuadernos Hispanoamericanos ${ }^{13}$. Era un intelectual claramente enmarcado en un pensamiento español que intentaba tanto reivindicar como enriquecer, por tanto no podemos desdeñar la utilidad del intento de desentrañar también los referentes intelectuales españoles en su obra, incluso hasta en la más plenamente enmarcada en la disciplina Historia de las Religiones, donde no resultaba evidente su presencia. Y puede servir de claro ejemplo de este interés por lo español que, justamente, dedicase su lección primera como catedrático de la materia en octubre de 1954 a este tema, bajo el título El saber histórico-religioso y la ciencia española ${ }^{14}$.

Intentaremos revisar esta doble, y necesariamente desigual vertiente, teniendo en cuenta tanto las citas y referencias (sustanciales, no circunstanciales o muy especializadas) que forman el aparato de sus trabajos publicados, como las reseñas que redactó y las apreciaciones y datos que sobre diversos autores que influyeron en su pensamiento pueden detectarse en su correspondencia.

\section{Mircea Eliade como principal referente intelectual}

Sin duda su referente intelectual más claro fue Mircea Eliade. No sabemos si Álvarez de Miranda pudo haber asistido en persona a alguna de las conferencias que dictó en Roma. Cabe quizá la posibilidad de que hubiera estado presente en la conferencia sobre el chamanismo que desarrolló, invitado por Pettazzoni, en la Universidad de

8 «Puedes estar seguro que cuentas en todo momento con mi decidido apoyo y que, a Dios gracias, seguirás ahi hasta que te interese venir a nuestra Universidad», se trata de un párrafo de una carta fechada el 4 de diciembre de 1951 que le envía el ministro Ruiz-Giménez y que recoge Pedro Álvarez de Miranda (Díez de Velasco/Álvarez de Miranda 2010, 557). Para un análisis detallado de las circunstancias de la cátedra véase Díez de Velasco 2007b, 95-109.

9 En Cisneros, suplemento 2 (1943) 6 aparece una nota anónima de enhorabuena ilustrada con una caricatura de A. Cadarso. Castro s/f, 73 escribe: era «la gran figura de nuestra promoción». En general Lago 2009.

10 Álvarez de Miranda 1943a-b (una reseña y una nota sobre el nieto de Renan); 1946 (un prólogo); 1947 (un corto artículo de opinión sobre el arte religioso); 1948b-e (una nota sobre el pecado y otra sobre el mesianismo, una edición del Fedón de Platón con una larga introducción, además de la traducción de un libro de Maritain (que luego repasaremos al tratar de Aranguren), autor al que ya había citado en su segundo trabajo publicado: Álvarez de Miranda 1943b, 100).

11 Álvarez de Miranda 1950a, lo publicó ya estando en Italia tras ganar el premio Mundo Hispánico 1949.

12 Lo expone claramente Ruíz-Giménez 1959, XI y el propio Laín 1959, IX ss.

13 Pérez Embid 1954, 21ss. indica que fue el primer secretario de Cuadernos Hispanoamericanos. Sobre Alférez destaca el detallado estudio de Lago 1992, en general Díaz Hernández 2007, 207-208 (para Cisneros); 211-212 (para Alférez) y 214-215 (para Cuadernos Hispanoamericanos). Agradezco a Antonio Lago Carballo su ayuda e informaciones sobre Álvarez de Miranda y su círculo de amistades, al que pertenecía.

14 Álvarez de Miranda 1955a. 
Roma el 23 de marzo de 1950, o en la del 25 en el ISMEO (Istituto per il medio ed estremo Oriente), invitado por Giuseppe Tucci, en la que habló de chamanismo y tantrismo ${ }^{15}$. Ambas marcaron un punto de inflexión en la internacionalización del impacto del pensador rumano a decir de su biógrafo Florin Turcanu ${ }^{16}$. El propio Eliade comenta que en la Universidad de Roma (en la que estudiaba en ese entonces Álvarez de Miranda) habló ante una gran sala, el aula prima, abarrotada ${ }^{17}$. Volvió Eliade a ofrecer en Roma una conferencia el 7 de mayo de 1952, de nuevo en el ISMEO, invitado por Tucci, y con presencia de Pettazzoni, sobre el tema de los lenguajes secretos y las técnicas místicas. Recordemos que se trata de la época en que Álvarez de Miranda está ultimando (si no lo había hecho ya) la redacción de su tesis doctoral bajo la dirección de Pettazzoni (que defenderá el 15 de noviembre ${ }^{18}$ ). Además, el 10 de mayo, ante una audiencia escogida en la que, junto a Tucci y Pettazzoni, se incluyen varios jóvenes (de los que no se dan los nombres), Eliade expuso de modo improvisado planteamientos sobre el método en historia de las religiones $^{19}$. Seguramente Álvarez de Miranda no estuvo presente, porque al tratarse de una reunión restringida hubiera sido necesariamente presentado a Eliade y veremos más adelante que de la correspondencia posterior entre ambos se extrae que no tenían ese grado de conocimiento personal. Pero es de suponer que la influencia que Eliade tenía en el Pettazzoni de este momento, y que ha analizado detallada y pertinentemente Natale Spineto ${ }^{20}$, no pudo dejar de llegar a sus oídos de modo directo o indirecto. Esta fecha de mediados de 1952, como veremos después, es significativa por la inclusión por parte de Álvarez de Miranda de citas de Eliade en sus trabajos. Eliade estuvo también presente previamente en la reunión constitutiva de la Società italiana di storia delle religioni del 18 de abril de 1951, pero aunque Álvarez de Miranda había sido convocado (con el erróneo e italianizado nombre de Angelo de Miranda) no se incluye su firma entre los presentes, aunque aparece (y con la grafía correcta del apellido) unos días después en el listado posterior de socios $^{21}$. Desde luego hubiéramos podido saber algo más de este tema, que permitiría fechar claramente el momento en el que el español tuvo conocimiento del trabajo eliadiano y, además, viniendo de la propia pluma de Álvarez de Miranda, si su correspondencia con Eugenio d'Ors no se hubiera interrumpido por la muerte de éste. En efecto en una carta fechada el 22 de agosto de 1954 (es decir un mes antes de la muerte de su autor, ocurrida el 25 de septiembre) d'Ors pide a Álvarez de Miranda, que en ese momento (desde finales de julio) ya era catedrático de Historia de las Religiones en la Universidad de Madrid, su opinión sobre Eliade, al que conocía de antiguo y con

15 Gandini 2006a, 158, la correspondencia asociada en Eliade/Pettazzoni 1994, 223-226. La problemática relativa al libro de Eliade y su impacto la analiza con detalle y perspicacia Casadio 2014, 31-58.

16 Turcanu 2003, 390-391.

17 Eliade 1973, 119 y 2004, 165-166 (no recogido en ninguna de las dos traducciones españolas), más desarrollado en Eliade 1988, 142-143. Dictó una tercera conferencia, repetición temática de la primera, en la Associazione per il progresso degli studi morali e religiosi (Gandini 2006a, 158-159) en la que la presencia de Álvarez de Miranda sería quizá menos probable.

18 Lo desarrolla Gandini 2007a, 39.

19 Eliade 1973, 176; 1979, 112-113; 2001, 116; 2004, 225-226; más resumido en Eliade 1988, 163-164, también Gandini 2007a, 18-19

20 En especial en Spineto 2006, 93-131; 2015, 485-496 y en su presentación en la antes citada (en la nota 1) jornada académica de homenaje a Ángel Álvarez de Miranda en la que propuso con acierto que el español fue, de entre sus discípulos, el más cercano en este aspecto a su trayectoria de los últimos años de vida.

21 Gandini 2006b, 133-134; 138-140, aparece como socio ya en diciembre de 1951 (Gandini 2006b, 199) 
el que se había relacionado epistolarmente en los últimos años y había citado en sus glosas en varias ocasiones (en algún caso de modo monográfico) de manera admirativa no exenta de crítica ${ }^{22}$. Se expresa d'Ors en los siguientes términos:

También quisiera saber su opinión sobre los libros de Mircea Eliade, a quien, hace tiempo, conocí personalmente en Lisboa, y a quien he leído mucho, tanto en un breve opúsculo sustancioso, como «El eterno recomenzar», que me impresionó mucho, como en la «Historia de las religiones», que publicó Payot y en que, a mi parecer, se abusa de la referencia detallista y prejudicial ${ }^{23}$.

Sin duda Álvarez de Miranda, de haber asistido a alguna conferencia de Eliade en Roma, lo hubiera detallado en su contestación a d'Ors, pero ésta, dirigida ya a los deudos del amigo, se resumió en un simple telegrama de condolencia por su fallecimiento. Y es que Álvarez de Miranda y d'Ors cultivaron una amistad teñida de admiración por parte del primero hacia el segundo (al que nombra como «querido maestro», aunque cita solo de modo esporádico y circunstancial en sus trabajos ${ }^{24}$ ), y de expectación por sus logros y apoyo del segundo hacia el primero y también hacia su esposa, Consuelo de la Gándara. Se trató de una amistad que se había consolidado en Roma, pues d'Ors había dictado el 21 de junio de 1949 la conferencia inaugural oficial del Instituto dirigido por Álvarez de Miranda y habían tenido diversos contactos con posterioridad (y hasta otra conferencia en 1952) ${ }^{25}$. Añádase que d'Ors había hablado y escrito en la prensa sobre la labor de ambos esposos en Roma $^{26}$ y también sobre la cátedra de historia de las religiones en los mismos días en los que se dirimía, sin citar de modo explícito a Álvarez de Miranda, pero usando a Eliade como pretexto para introducir el tema, que puntualiza que le interesaba muy especialmente ${ }^{27}$.

22 Cuestión revisada con detalle en Díez de Velasco 2009.

23 La carta se recoge completa en Díez de Velasco 2007a, 65 (texto 6c; se conserva en el archivo privado de los herederos de Ángel Álvarez de Miranda a quienes agradezco el acceso), así como la previa de Álvarez de Miranda del 10 de agosto de la que aquella es contestación (64-65, texto 6b; se conserva en el Arxiu Nacional de Catalunya, en el fondo Eugeni D’Ors).

24 En su segundo gran artículo (Álvarez de Miranda 1945b, 32, nota 1) incluye a d'Ors en una cita en una nota (y junto a Ortega), sin ahondar en el contenido o detallar la obra pero refiriéndose claramente al trabajo dorsiano sobre «Cúpula y monarquía», que por otra parte interesó mucho a Eliade. Le dedica un pequeño párrafo en la reseña al Breviario del Quijote de Eduardo Caballero Calderón (Madrid, Aguado, 1947), citando una glosa dorsiana dedicada al mismo tema en la que se evocaba el «evo» y la angelología (Álvarez de Miranda 1948a, 363). Dos meses más tarde en otra reseña (Álvarez de Miranda 1948g), en este caso al libro de Emilio Orozco, Temas del barroco (Granada, Universidad, 1947) hace otra cita de aluvión, imprescindible por la relevancia de los planteamientos dorsianos respecto del asunto plasmados en una monografía publicada primero en francés y luego tres años más tarde vertida al español (d’Ors 1935; 1944). En ningún caso se trata de citas relevantes, pese al aprecio que Álvarez de Miranda le demuestra en sus cartas.

25 Lo detalla Pedro Álvarez de Miranda (en Díez de Velasco/Álvarez de Miranda 2010, 556-558).

26 D’Ors 1949 a-c.

27 D’Ors 1954b (recogida parcialmente en Díez de Velasco 2007a, 64 (texto 6a) donde dice: « Según mis noticias, pronto va a ser instaurada, en la Universidad de Madrid, la cátedra de «Historia de las religiones»... A mí, particularmente, semejantes cuestiones me interesan mucho; porque, sin ser, ni mucho menos, especialista, he tenido que tropezar con ellas...». Este interés lo ilustra, por ejemplo, también una carta dirigida a José Luis López Aranguren fechada el 21 de septiembre (cuatro días antes de la muerte de d'Ors) en la que dice: «Espero que $V$. me dé noticia de lo de la nueva cátedra de Historia de las religiones para la cual también nuestro amigo Álvarez de Miranda ha sido cortado por la enfermedad» (la carta se encuentra en el Archivo Aranguren en el CSIC en Madrid, signatura: AFI-AA-CO-O2-3006-39). De modo explícito d'Ors (1954a) había citado a Álvarez de Miranda en una glosa en mayo. 
De las cartas entre Eliade y Álvarez de Miranda se han conservado dos y es difícil saber por ellas si el español había escuchado en persona alguna conferencia del rumano. Falta una primera, enviada junto con la separata de una reseña que Álvarez de Miranda dedicó a la publicación en español del Tratado de historia de las Religiones de Eliade $^{28}$ y que debió de fecharse en febrero. Eliade le contesta el 10 de marzo terminando la frase por un «congratulándome de modo anticipado por que podamos conocernos personalmente en el próximo congreso de Roma, reciba, querido colega, mi saludo cordial $\rangle^{29}$, es una redacción que daría a entender que aún no habían tenido un contacto en persona. Por su parte la contestación de Álvarez de Miranda del 21 de octubre usa una fórmula que no descarta que hubiese visto a Eliade con anterioridad, pero sin haber entablado una conversación, pues dice:

[...] hubiera sido feliz si hubiera podido conversar con Vd. en el congreso de Roma. Desdichadamente, sin embargo, me hallo paralítico desde hace casi un año $\mathrm{y}$ tengo que renunciar entre otras cosas a hacer una vida intelectual todo lo intensa que esperaba realizar cuando obtuve mi cátedra de Historia de las Religiones de la Universidad de Madrid ${ }^{30}$.

Si bien Mircea Eliade publicó su Tratado en París en 1949, la revisión de la obra escrita de Álvarez de Miranda no permite hallar a Eliade citado hasta que aparece en una nota (y no en el texto) en un contexto en el que utiliza también a Rudolph Otto (este sí citado también en el texto) donde se analiza la bipolaridad religiosa. Sabemos que el pasaje fue redactado entre julio y diciembre de $1952^{31}$ y publicado a finales de 1953 en una nueva revista que había fundado Pedro Laín y que con el tiempo, tras cambiar de nombre, se llamará Asclepio y perdura hasta hoy. El pasaje plantea la cuestión en los términos que siguen:

Pero las prácticas que hemos encontrado en el mundo grecorromano muestran otra particularidad que también induce a percibir por debajo de su carácter medicinal otro aspecto de la secularización de una originaria intuición religiosa: se trata de la oscilación medicina-veneno atribuida, sobre todo, a la sangre de toro. El historiador de la medicina griega conoce de sobra esta bipolaridad, cuya más patente revelación está contenida en el doble sentido de la palabra pharmakos. Ese género de oscilaciones son uno de los patrimonios característicos de lo numinoso que no pasó inadvertido al penetrante análisis de Otto sobre lo sagrado, y que la ciencia de las religiones comprueba a cada paso ${ }^{32}$. Pero tal bipolaridad o ambivalencia es

28 Álvarez de Miranda 1955c.

29 «En me réjouissant d'avance de faire votre connaissance personnelle à l'occasion du Congrès de Rome, je vous prie d'agréer, Cher Collègue, l'expression de mes sentiments les meilleurs». La carta se conserva en el archivo de los herederos de Álvarez de Miranda a quienes agradezco el acceso a esta correspondencia.

30 Esta correspondencia se recoge en Díez de Velasco 2007a, $69-70$ (texto 10 b-c). Se custodia en la Biblioteca Regenstein de la Universidad de Chicago, fondo Eliade, caja 65 (agradezco a Álvaro Santana Acuña, a Mircea Handoca y a Mac Linscott Ricketts su ayuda, en relación con la búsqueda y acceso a esta documentación).

31 En la recopilación póstuma de los trabajos de Álvarez de Miranda (1959a-b) que hace su viuda, Consuelo de la Gándara, no se citó la fuente de publicación de los trabajos (hay que tener en cuenta que algunos eran inéditos pero otros eran monografías o artículos como el que repasamos), pero sí se incluye siempre la fecha de confección, que en este caso es muy interesante puesto que desde que lo escribió a que se publicara pasó casi un año y nos interesa detectar y evidenciar que es el primer artículo que confeccionó tras la redacción de la tesis italiana.

32 Aquí cita el Tratado de Eliade en su edición francesa. 
sobre todo perceptible en el tema mismo de la sangre, que para el hombre primitivo y arcaico es la vida misma... ${ }^{33}$

Dos puntos resultan curiosos en esta cita, el primero es que prefiere aquí «ciencia de las religiones» para el nombre de la disciplina, asunto que revisaremos más adelante, y el segundo, la cuestión de que no hubiese citado a ninguno de los dos autores en la investigación principal, su tesis italiana, de la que este artículo es la primera de las tres secuelas principales que confeccionó ${ }^{34}$, y a pesar de lo pertinente que hubiera resultado, desde luego, la cita eliadiana ${ }^{35}$. Pero lo que no deja dudas es que en este momento y en este artículo ya había comenzado la inoculación de la terminología eliadiana y, por ejemplo, el uso de lo arcaico en este trabajo difiere del que hizo en la tesis en varias ocasiones y está muy cercano al que emplea Eliade. Que no cite a Eliade en la tesis italiana quizá se debió a que no apreciaba todavía en toda su potencialidad la obra del rumano, que «descubre» justamente en los meses que median entre que termina de redactar la tesis y comienza a redactar este artículo. Es la época de la visita a Roma de Eliade de mayo de 1952 antes repasada, de su conferencia en el ISMEO y de su sesión restringida sobre metodología. Álvarez de Miranda ya había terminado la primera redacción de la tesis, puesto que se conservan en el archivo Pettazzoni unas anotaciones de su maestro fechadas el 5 de junio ${ }^{36}$. Por tanto, cuando se estaban desarrollando las conferencias de Eliade, Pettazzoni estaba leyendo el borrador del trabajo de Álvarez de Miranda. Es muy posible que, de modo directo o por lo que le contaron otros (quizá el propio Pettazoni), supiese del impacto de Eliade y le quedase claro que se trataba sin duda de un personaje imprescindible en la disciplina. Además, ya estaba en proyecto la traducción del Tratado al español, asunto del que podía saber algo Álvarez de Miranda por sus contactos (con el entorno de Xavier Zubiri en especial) y que desde luego conocía de modo probado unos meses después cuando en verano del año siguiente ya avanza en su trabajo sobre García Lorca que la traducción española del Tratado está a punto de publicarse ${ }^{37}$. Hay que tener en cuenta que la traducción la encargó Zubiri a Asunción Madinaveitia, que era pariente de su esposa, para la «Biblioteca de Cuestiones Actuales» que dirigía. Por su parte Zubiri y Eliade tenían una relación previa que se había plasmado, por ejemplo, en el nombramiento, para el Centre Roumain de Recherches, sito en París y liderado por Eliade, de Zubiri como miembro de honor ${ }^{38}$, y su aprecio al trabajo del rumano llevó a que tuviese alguna intervención en otras

33 Álvarez de Miranda 1953a; 1959b, 26 nota 5.

34 Álvarez de Miranda 1953a; 1954a; 1954d, asunto revisado en Díez de Velasco 2015, 72-76.

35 Por ejemplo Nappo 2012, 180-181, expone que el tratamiento que hace Álvarez de Miranda del tema sería solo comparable con el eliadiano.

36 Custodiado en la Biblioteca Comunale G. C. Croce en San Giovanni in Persiceto (Bolonia, Italia), que incluye una muy amplia documentación que Mario Gandini ha explotado de modo sistemático. El ejemplar personal de Pettazzoni de la tesis de Álvarez de Miranda incluye 16 páginas de minuciosas anotaciones y correcciones al texto que son una mina de información, además de un ejemplo de la meticulosidad con que Pettazzoni desarrollaba su labor de tutorización discipular. Las 8 primeras llevan la fecha de 5 de junio de 1952 y las ocho siguientes, correspondientes a la discusión de la tesis, la fecha de 25 de noviembre. Agradezco a Mario Gandini el acceso a los fondos del Archivo Pettazzoni y la correspondencia allí custodiada (y citada en diversos momentos a lo largo de este artículo) y a estas anotaciones inéditas en especial, así como las diversas informaciones y correspondencia entablada entre nosotros al respecto a lo largo del último decenio.

37 Álvarez de Miranda 1953c; 1959b, 76-77; 2010, 132-133.

38 Se conserva una carta del 15 de agosto de 1950 firmada por Eliade con el nombramiento (se custodia en la Fundación Zubiri de Madrid, a cuyos responsables agradezco el acceso). 
traducciones así, por ejemplo, su esposa, Carmen Castro, en estos años, fue la traductora del libro de Eliade Imágenes y símbolos, para la editorial Taurus, que se publicó en 1955 y cuya primera edición en francés es de 1952.

Además, podríamos incluso especular que, a mediados de 1952, Álvarez de Miranda quizá empezaba ya a vislumbrar como muy posible, sino inminente, el proyecto de poder llegar a tener que competir a una cátedra de Historia de las Religiones en la Universidad Central de Madrid, puesto que la primera carta que dirige a Santiago Montero exponiéndole su vocación y sus planes, que se fecha el 8 de octubre, ya la escribe sabiendo que cuenta con el apoyo para ello de las autoridades del ministerio y de la universidad (el ministro Ruiz-Giméne ${ }^{39}$ y el rector Laín). Álvarez de Miranda debía sentir que tenía que abrirse a perspectivas menos específicas y más ambiciosas en sus análisis y Eliade, que combinaba un encuadre disciplinar claro con una capacidad destacada para el análisis y la clasificación temática (al modo de la fenomenología), resultaba un referente intelectual muy conveniente.

En su siguiente trabajo publicado tras la tesis italiana, que emprende en el verano de 1953 y dedica al análisis de los elementos míticos y religiosos en la obra de García Lorca y titula «Poesía y religión», Eliade tiene una muy notable presencia. Lo redacta una vez que ha conseguido terminar su tesis española, bajo la dirección de Santiago Montero Díaz, que lee el 29 de mayo de 1953, que ha confeccionado demasiado deprisa y no le ha satisfecho ${ }^{40}$, pero que era imprescindible terminar a tiempo para poder optar a la oposición a cátedras. Conocemos varias versiones de este trabajo de tema lorquiano que es quizá su obra más interesante, creativa y puntera, y que todavía actualmente se reedita y aprecia. Se publicó en primer lugar, en una versión recortada de casi la mitad de su contenido, en la Revista de ideas estéticas, en el número de 1953; la versión completa la presentó a la oposición de cátedras como trabajo independiente, preludiando una monografía que deseaba que hubiese llevado el título de Poesía y religión. Descenso al antro de García Lorca; se publicó póstumamente en 1959 en el segundo tomo de la recopilación Obras, manteniendo solo el título de «Poesía y religión»; fue retomada como monografía en 1963 bajo un nuevo título, La metáfora y el mito (que le puso el director de la colección Cuadernos Taurus donde aparecía, y que era el entonces padre Jesús Aguirre), y ha sido reeditada en 2010 con un subtítulo nuevo: Intuiciones de la religiosidad primitiva en la obra de Lorca. En esta obra cita a Eliade en una decena de ocasiones (es el autor más citado en este trabajo junto con Gerardus van der Leeuw), incluyendo diversos pasajes de sus obras en el texto y haciendo de él un uso sistemático ya que, para sostener su aproximación comparada al universo simbólico del poeta granadino, le resultaban

39 Ya vimos que meses antes le había escrito dejando abierta la posibilidad de entrar en la universidad. RuízGiménez desde el ministerio y Laín desde la universidad de Madrid (que en este momento aglutinaba a la mitad de los profesores universitarios de España) intentaban atraer talentos y nuevas disciplinas y perspectivas después de los años de purgas del largo decenio del ministerio de Ibáñez Martín. Les interesaba Álvarez de Miranda y apoyaron su candidatura del mismo modo que hicieron también, por ejemplo, con José Luís López Aranguren, por la excelencia e inteligencia de ambos, a la que se añadía que pertenecían a su círculo de amigos y colaboradores. Aunque expresase a Montero sus dudas en una carta fechada el 23 de marzo de 1953, no deja de invocar el interés de unos amigos comunes que no son sino los que gestionan la universidad y el ministerio, dice lo siguiente: «Me dice Vd. que está a punto de dotarse una cátedra de Historia de las Religiones: si le he de decir la verdad siempre me han asaltado dudas de que ese proyecto pueda realizarse en España (sobre todo tan pronto como parece deducirse de su carta) a pesar del deseo de comunes amigos nuestros».

40 En su carta del 31 de marzo de 1953 dice: «...mañana... llegarán a Madrid los 5 ejemplares de la tesis... Pienso en lo bastante mejor que el trabajo podría haber resultado si no hubiera habido estas prisas...». 
muy útiles los instrumentos de interpretación que la morfología de lo sagrado eliadiana le brindaban en lo relativo a la sangre y la luna, temas lorquianos fundamentales. Respecto de la sangre, la primera cita eliadiana le sirve para repetir la idea, ya planteada en el artículo previo sobre la medicina del toro de forma muy semejante, de la bipolaridad o ambivalencia como cuestión bien analizada por la historia de las religiones, usando a Otto y a Eliade como referencias en notas ${ }^{41}$. La segunda cita la utiliza para apoyar la conexión sangre-fecundidad-sexualidad y emplea el concepto eliadiano de «solidaridad de las hierofanías» citando a su autor expresamente en el texto y las notas ${ }^{42}$. Se trata de un concepto que vuelve a repetir más adelante, citando a Eliade en el texto, al relacionar sacralidad de la sangre y sacralidad del mundo vegetal y que conecta por medio del concepto de religación, de claro aroma zubiriano, con la sacralidad lunar ${ }^{43}$. En el resto de las citas es la luna la que lleva a Álvarez de Miranda a referirse al pensador rumano, asunto por otra parte ineludible dado que el análisis de la importancia de lo lunar en la religión comparada es uno de los capítulos más destacados del Tratado de Eliade. La primera cita de este asunto es de aluvión sobre la importancia de la luna entre lo que denomina «una legión de estudiosos», pero singularizando en una nota la obra de Eliade del siguiente modo:

A esta última obra se hará una más frecuente alusión a lo largo de estas páginas en todo lo referente a la divinidad lunar, tanto por tratarse de un libro especialmente asequible para el lector español (está a punto de aparecer la versión española), cuanto por el excelente resumen que en ella ofrece el gran historiador rumano sobre la materia ${ }^{44}$.

Otras tres citas incluyen frases del libro de Eliade en el texto y tienen que ver con la relación luna-ser humano. Destaca la relación entre el simbolismo lunar y los ritmos de la vida ${ }^{45}$ por una parte, entre la luna y la mortalidad por otra ${ }^{46}$ y en suma, de lo humano y lo lunar, por último, que resumido en palabras del Tratado que se citan en el texto plantea: «en la conciencia del hombre arcaico la intuición del destino cósmico de la luna ha sido equivalente a la fundación de una antropología. El hombre se ha reconocido en la vida de la luna ${ }^{47}$. Hay otra cita, más circunstancial, que se refiere a la relación luna-oso ${ }^{48}$, pero la última y más significativa de la importancia que otorgaba a Eliade en su análisis y hasta en la propia estructuración del trabajo,

41 Álvarez de Miranda 1959b, 58, nota 1; 2010, 44 (130, nota 19) donde solo aparece la cita de Otto.

42 «Asi de inexorablemente el tema de la sangre se entrelaza con los de la fecundidad, generación, sexualidad, etc. No podía ser de otra manera, puesto que para el poeta, como para la mentalidad arcaica, la sangre es la vida, y dado que la fecundidad y sus epifenómenos son, como ya vimos, otras tantas epifanías de la sacralidad de la vida. La historia de las religiones conoce bien este fenómeno que podemos llamar, con palabras de Eliade, «la solidaridad de las hierofanías»»): Álvarez de Miranda 1959b, 62 y nota 1; 2010, 51 (130, nota 22).

43 «Exactamente lo mismo sucede en la religiosidad arcaica: la sangre, una forma de la vida, está hermanada con esa otra forma de la vida que brota de la tierra bajo la numerosa especie del mundo vegetal. Millares de mitos y de ritos conocen y utilizan esa fraternal comunión entre la sacralidad de la vida orgánica (sangre) y la sacralidad del mundo vegetal. A ello ya hemos aludido viendo en ella un caso típico de lo que con Eliade llamábamos «solidaridad de las hierofanías». El principio de esta solidaridad, o, como decíamos nosotros, de esta religación, es, una vez más, la luna» (Álvarez de Miranda 1959b, 94; 2010, 99).

44 Álvarez de Miranda 1959b, 76-77, nota 1; 2010, 73 (132-133, nota 31).

45 Álvarez de Miranda 1959b, 77, nota 3; 2010, 74 (133, nota 34).

46 Álvarez de Miranda 1959b, 85-86, nota 1; 2010, 87 (134, nota 43).

47 Álvarez de Miranda 1959b, 104, nota 1; 2010, 117 (136, nota 55).

48 Álvarez de Miranda 1959b, 102, nota 1; 2010, 112 (135, nota 51). 
es la que cierra todo el estudio y donde desvela Álvarez de Miranda la propia acción intelectual que ha desarrollado en su obra, que entiende como un descenso al antro del poeta, una katábasis eis ántron, que permitiría dejar al descubierto, como en una iniciación mistérica, la esencia misma de las imágenes lorquianas. Pedro Álvarez de Miranda, en su presentación a la más reciente edición del libro ${ }^{49}$, ha desentrañado la clave para entender este proceder intelectual que conllevaba (y explica) que su padre quisiese subtitular con esas precisas palabras la obra en la versión definitiva como monografía que nunca pudo ver publicada. Sería la aplicación a Lorca de lo que Jung había esbozado, por ejemplo, con Picasso ${ }^{50}$. Todo el trabajo se cierra de la siguiente manera:

Así en la poesía de García Lorca, así en la religiosidad arcaica. Como resumen de nuestro «descenso al antro» del poeta se podría decir:

«La luna "religa" y agrupa, con sus normas, una inmensa cantidad de realidades y destinos. Armonías, simetrías, asimilaciones, participaciones, etc., coordinadas por los ritmos lunares, constituyen un "tejido" sin fin, un "tapiz" de hilos invisibles que "religa" a la vez hombres, lluvias, vegetación, fecundidad, salud, animales, muerte, regeneración, vida post mortem.»

¿De quién son y a quién se refieren estas palabras? Las ha escrito un gran tratadista de historia de las religiones y las ha referido a la arcaica religiosidad lunar. Pero podría hacerlas suyas la historia de la poesía española en el capítulo destinado a este nombre: Federico García Lorca. ${ }^{51}$

La siguiente obra que Álvarez de Miranda emprendió fue la redacción de su trabajo de investigación inédito obligatorio para presentar en la oposición a cátedras, cuyo preámbulo está fechado en octubre de 1953 y que tituló «Las religiones mistéricas y el problema de su inserción en la historia general de las religiones». Cita a Eliade en una sola ocasión en el capítulo que dedica a repasar el papel que se otorga en los manuales de la disciplina a las religiones mistéricas. Tiene una posición muy crítica frente a todos ellos y piensa que no sitúan en su correcto nivel (el máximo en su opinión) a las mistéricas y defiende una clasificación de religiones en cuatro grandes bloques: primitivas, nacionales, mistéricas y universales. Sitúa a Eliade con Gerardus van der Leeuw en lo que denomina «interés fenomenológico sobre el propiamente histórico» y plantea al respecto:

[...] la obra de Eliade, que a pesar de su título no es en rigor una historia de las religiones en el sentido tradicional, sino una inspección de los "temas" universales de la historia de las religiones desligados de su inserción temporal-espacial: pero aun dentro de esta dirección, extraordinariamente rica y original, es necesario recono-

\footnotetext{
49 Álvarez de Miranda 2010, 15 (127, nota 2)

50 El trabajo de Jung se fecha en 1932, recogido en Jung 1999, 129, Álvarez de Miranda debió leerlo en la traducción española titulada Realidad del alma, publicada por Losada en Buenos Aires en 1940. Al tema de Picasso ya le había dedicado una nota-recensión (Álvarez de Miranda 1948f) que se centraba en los temas religiosos, pero incidiendo en ribetes de antisemitismo que trasladaba del libro que reseñaba, homónimo del título de su trabajo, y obra de A. Cirici Pellicer. El asunto Jung-Picasso y el «descenso al antro» lo trató, con una perspectiva crítica (llama teoría extravagante a este análisis junguiano), dos años antes de «Poesía y religión», en un trabajo sobre el modernismo español (Álvarez de Miranda 1951, 371-372).

51 Álvarez de Miranda 1959b, 110-111, y nota 1; 2010, 125 (137, nota 62).
} 
cer que la obra de Eliade confiere muy somera atención a los temas propiamente mistéricos (iniciación, soteriología, escatología, figura del Salvador, etc, etc.) $\rangle^{52}$.

Sabemos por los escritos autobiográficos de Eliade que comenzó a redactar el Tratado en Inglaterra y que tuvo que ir reduciendo en su etapa portuguesa toda una serie de temas para que no desbordase en tamaño, así cuenta en el Diario portugués que quitó la parte correspondiente a los misterios en noviembre de $1944^{53}$ y la correspondiente a muerte e iniciación en julio de $1945^{54}$. Son justamente los temas que echa más de menos Álvarez de Miranda en su trabajo.

En los meses previos a la oposición, que se desarrolló entre finales de junio y comienzos de julio de 1954, escribió tres artículos, dos de ellos son excelentes trabajos de investigación dedicados a la cuestión de la irreligiosidad, que le interesaba muy particularmente, cargados de notas y de análisis muy documentados, uno dedicado a Job y Prometeo ${ }^{55}$ y otro, extraído de su tesis doctoral española, dedicado a Polibio ${ }^{56}$. Seguramente porque el tema estaba lejos de las inquietudes de Eliade, el rumano no aparece citado. El tercero es muy diferente, puesto que no incluye aparato de citas ni referencias bibliográficas (salvo una), lo redactó en junio de 1954 y se publicó inmediatamente en el número de ese mismo mes de Cuadernos Hispanoamericanos y le dio tiempo a presentarlo como mérito a la oposición (que comenzó para los opositores el 26 de junio). Trata del marianismo español ${ }^{57}$ y parece una obra de circunstancia, quizá pensada para disipar, por medio de una contribución a la disciplina mariológica (uno de los puntos fuertes de la teología española), las dudas que pudiese albergar respecto de su persona y de los derroteros por los que podía discurrir la historia de las religiones en la universidad española alguno de los religiosos miembros del tribunal ${ }^{58}$. Y es que la existencia de una cátedra de este tipo podía concitar lo contrario que apoyos y fue un asunto que quedó patente tras la muerte de Álvarez de Miranda cuando, no sin múltiples vicisitudes y retrasos, diez años más tarde de la primera, quedó finalmente declarada desierta y paralizada sine die la cátedra de Historia de las Religiones nuevamente convocada $^{59}$. Álvarez de Miranda en este artículo emplea en dos ocasiones el término mariofanía, que si bien había forjado tiempo atrás Jean Guitton, cuya obra específica era conocida en España por su traducción aparecida dos años antes ${ }^{60}$, parece utilizar en una acepción muy eliadiana, al modo de una hierofanía. Hemos visto como Álvarez de Miranda en «Poesía y religión» ha citado en dos ocasiones las hierofanías de Eliade. En la larga reseña que publicará en 1955 dedicada a la traducción española del Tratado de historia de las religiones ahonda en la asocia-

\footnotetext{
Álvarez de Miranda 1961, 16-17, en la nota 31 da la referencia del Tratado de Eliade.

Eliade 2001, 268; 2006, 157.

Eliade 2001, 367-368; 2006, 240.

Álvarez de Miranda 1954b.

56 Álvarez de Miranda 1956, pero lo redactó en 1954 ya que lo presentó en pruebas de imprenta a la oposición, tardó por tanto dos años en publicarse de modo definitivo.

57 Álvarez de Miranda 1954c.

58 No sería el padre Ricardo García Villoslada, que Álvarez de Miranda conocía bien de Roma y de la Universidad Gregoriana y entre ambos existía un mutuo aprecio; asunto distinto era el padre Alberto Colunga, miembro titular que renunció y también el padre Justo Pérez de Urbel, que finalmente formó parte del tribunal y cuya trayectoria no deja dudas de su posicionamiento.

59 Se exponen las circunstancias en Díez de Velasco 2007b, 118-125.

60 Guitton 1952.
} 
ción y expone: «manifestaciones de lo sagrado (hierofanías, según el afortunado neologismo del autor) ${ }^{61}$. Se puede defender que al usar mariofanía en este trabajo de 1954 Álvarez de Miranda no solo seguiría el neologismo de Guitton, sino que lo impregnaría de aroma eliadiano.

La siguiente cita de Eliade le sirve a Álvarez de Miranda para apuntalar su apuesta por la denominación Historia de las Religiones para la disciplina a la que se dedica y para justificar el nombre de la cátedra de la que ya es titular. Se trata de un opúsculo monográfico que refleja la primera lección de cátedras que dictó ante un auditorio muy numeroso en octubre de 1954. El problema del nombre ya había sido un tema tratado en las cartas entre Montero y Álvarez de Miranda del año anterior. El primero, quizá por su formación más orientada hacia la perspectiva científica alemana, prefería Ciencia de la Religión (Religionswissenchaft), en singular ambos elementos, y de hecho parece que entendía la Historia de las Religiones como una subdisciplina de la Ciencia de la Religión y hermanada con la Filosofía de la Religión, como se desprende de la correspondencia entre ambos ${ }^{62}$. El segundo, aunque como adelantamos, había hablado en algunas ocasiones (incluso desde $1948^{63}$ y hasta en los trabajos que manda a publicar en los meses aledaños a la oposición ${ }^{64}$ ) de la disciplina bajo la acepción de Ciencia de las Religiones, pluralizando el segundo elemento y por tanto apostando por la diversidad de manifestaciones (religiones) frente a la singularidad del fenómeno (la religión como concepto), se decanta en 1954 principalmente por Historia de las Religiones y en su primera lección se encarga de exponerlo de modo diáfano cuando dice:

Es sabido que la denominación misma de «Ciencia de las Religiones» ha querido emplearse en sustitución de la tradicional denominación «Historia de las Religiones», sobre todo en ambientes anglosajones y germánicos de principios de siglo.

Álvarez de Miranda está entendiendo ambas denominaciones como equivalentes y plantea que la apuesta por la primera tendría que ver con criterios lingüísticonacionales. Es en el siguiente párrafo donde introduce a Eliade en la reflexión como referencia de autoridad:

61 Álvarez de Miranda 1955c, 110.

62 En una carta del 16 de marzo de 1953 dice Montero: «la cátedra, a punto de dotarse, de nuestra Facultad, que llevará el título de Historia de las Religiones, o Filosofía de la Religión»; le contesta Álvarez de Miranda el 23 de marzo en una postdata: «Me dice Vd. que el título de la cátedra parece que será "Historia de las Religiones" o bien "Filosofia de la Religión". Estoy seguro de que Vd., lo mismo que yo, preferirá el primero: sin la Historia será imposible la Filosofia: no se trata de excluir a esta última, por supuesto; pero creo que Vd. mejor que nadie, como historiador y como todo, puede influir para que la nueva disciplina se incluya como Historia de las Religiones. Desde luego a mí me conviene mucho más así, pero estoy convencido que a la Universidad misma y al enfoque de la disciplina le conviene no menos esta formulación de "Historia”. ¿No cree?». Montero el 5 de mayo expone del modo más diáfano su punto de vista y la categorización que hace entre disciplina (Ciencia de la Religión) y sub-disciplina (Historia de las Religiones): «una cátedra que en definitiva tratará de Ciencia de la Religión (subrayado a mano en la carta). Esta es una necesidad que se deja sentir. Se trata de decidir si la "especificación" de la cátedra será "Historia de las Religiones" o "Filosofía de la Religión". Hasta ahora nada hay firme sobre eso, y yo tengo la seguridad de lograr, en la Junta de Facultad, el desempate en el sentido de "Historia comparada de las religiones" o algo análogo» (esta cuestión se repasa en Díez de Velasco 2007b, 100ss, y en especial 2007a, 25-26 y 61-63 - con los textos completos de las cartas-).

63 En su reseña sobre el libro, recién traducido en ese entonces, de Romano Guardini sobre el mesianismo (Álvarez de Miranda 1948c, 351).

64 Álvarez de Miranda 1956, nota 1; 1959b, 383, recordemos que es un texto que presentó en pruebas a la oposición y por tanto es de redacción anterior a junio de 1954. 
El problema de una ciencia de las religiones, si por un lado plantea inexcusablemente la cuestión denominativa, en la realidad se desentiende, a la hora actual, de buscar e imponer una nueva solución nominal y enunciativa, y prefiere acogerse a la tradicional rotulación, ya consagrada por el uso, de «Historia de las Religiones». Incluso autores de la hora presente que se orientan hacia una dirección fenomenológica, como Mircea Eliade, no vacilan, sin embargo, en adoptar para su obra el viejo título de «Historia de las Religiones» ${ }^{65}$.

Álvarez de Miranda no pudo, por la enfermedad cuyos síntomas se manifestaron ya en los días en que desarrollaba la oposición y fueron empeorando muy rápidamente hasta dejarlo inválido, producir las obras que planeaba, entre las que se contaba posiblemente un manual de historia de las religiones en español ${ }^{66}$, en el que las referencias a Eliade hubieran sido numerosas, ya que en sus clases usaba mucho al rumano como indicó en su correspondencia, que luego revisaremos. Lo que si escribió fue una reseña de cuatro páginas analizando la antes citada traducción del Manual de Eliade poco después de su aparición. La redactó a finales de 1954 y apareció en el primer número, de 1955 (el de enero), de Cuadernos Hispanoamericanos y el tenor de la misma es muy elogiosa aunque no exenta de puntualizaciones críticas. Frente a la posición que había mantenido Eugenio d'Ors y que ya adelantamos, ya que el Manual no le había gustado, esta reseña puede servir de contestación a la última carta antes citada entre d'Ors y Álvarez de Miranda que nunca llegó a escribir el segundo por la defunción del primero. Las palabras de Álvarez de Miranda son muy claras.

Manuales de historia de las religiones existen por docenas desde finales del siglo pasado. Entre todos ellos, éste de Eliade, aparecido en Francia en 1949, ocupa ya un puesto singular y será siempre señalado por su originalidad en el modo de tratar la materia. Esa originalidad consiste, para decirlo en pocas palabras, en haber sustituido la tradicional arquitectura de los tratados similares, que ha sido siempre primordialmente histórica, por otra arquitectura hasta ahora inusitada, que es rigurosamente temática [...] Ninguna religión y ningún fenómeno religioso ha pretendido ser estudiado, lo cual no obsta para que el saber históricorreligioso más minucioso y rico forme la verdadera trama del libro. Solo que los hilos conductores de esa trama, en vez de las diversas religiones, son los temas religiosos en sí mismos, como elementos que, de una u otra manera, aparecen en múltiples sistemas religiosos [...] Todo esto significa que la originalidad de este libro consiste en haber elegido un punto de vista resueltamente fenomenológico para una materia que en los libros de similar finalidad venía siendo objeto de tratamiento exclusivamente histórico. Hay una fórmula verbal que el autor emplea casi constantemente: en no importa que lugar... se da tal o cual sacralidad, que Eliade agrupa con las similares de cualquiera otra religión, prescindiendo de su ubicación en tiempo y espacio. Semejante prescindencia típicamente fenomenológica plantea, sin embargo, una cuestión: la de hasta qué punto es lícito para una obra así arrogarse el título tradicional de «Historia de las religiones», dado que aquí se pone entre paréntesis el coeficiente temporal y espacial, esto es, histórico, de las sacralidades. Es ésta una 
objeción que más de un estudioso ha formulado ya a Eliade. Objeción razonable, sin duda alguna, pero que atañe más al título que a su contenido. Por otra parte, el mismo Eliade parece concebir su libro como la primera etapa de un trabajo más amplio, en el que, indudablemente, ofrecerá la complementaria perspectiva histórica, de la que deliberadamente ha prescindido aquí. Si tal no fuese su proyecto, el título de este libro sería menos justificable; y su puesto en las bibliotecas estaría muy cerca al de la Phänomenologie der Religion, de Van der Leeuw, la cual es una óptima compañía, sin duda alguna, pero inadecuada para hacer entrar a una obra en el recinto mismo de los tratados historicorreligiosos, que es lo que merece, en definitiva, el producto intelectual de un estudioso como Eliade. Porque lo principal es esto: que nos hallamos ante un libro riquísimo en datos y fenómenos historicorreligiosos [...] construido con una sensibilidad asociativa para lo religioso que el lector poco habituado a estos asuntos quizá no valore lo suficiente [...] y hay motivos para suponer que varios de los conceptos y expresiones forjados por el autor se harán clásicos [...] La temática religiosa ocupa cada vez más, en todas partes, un primerísimo plano de la vida intelectual, y pocos libros más aptos que este de Eliade para desarrollar un tipo de sensibilidad no muy floreciente en nuestras latitudes» ${ }^{67}$

Ya vimos que Álvarez de Miranda había enviado la reseña a Eliade con una carta que no ha aparecido (por el momento), pero sí se ha conservado la carta de contestación, en lengua francesa, fechada el 10 de marzo de 1955, en la que Eliade se justifica respecto de los argumentos de Álvarez de Miranda y adelanta que está preparando una segunda parte del manual que servirá para resolver la cuestión. Y dice:

Quería en todo caso decirle lo mucho que está en lo cierto al recordar que este primer volumen -fenomenológico y morfológico- no se corresponde al título general de la obra. Tengo en preparación desde hace bastante tiempo, y espero terminarlo de aquí a dos o tres años, un segundo tomo que llevará por subtítulo, El hombre, lo sagrado y la historia, y estará dedicado a los ritos y la historia propiamente dicha de las religiones ${ }^{68}$.

Evidentemente Eliade no podía contar la verdad, y es que hubiera querido titular su libro «Prolegómenos al estudio comparado de las religiones», que es como lo nombra en el Diario Portugués, pero que el título definitivo se lo había puesto su editor, Gustave Payot, con finalidades comerciales ${ }^{69}$. Este título de Prolegomenele

67 Álvarez de Miranda 1955c, 109-112.

68 Conservada en el archivo privado de los herederos de Álvarez de Miranda, el pasaje dice: «Je voulais pourtant vous dire combien vous avez raison en rappelant que ce premier volume -phénoménologique et morphologique-ne correspond pas au titre général de l'ouvrage. Un second tome-qui aura comme soustitre, L'Homme, Le Sacré et l'Histoire-, et qui sera consacré aux rites et à l'histoire proprement dite des religions, est depuis longtemps en préparation: j'espère qu'il sera achevé d'ici en deux, trois ans.» Eliade fue posponiendo el proyecto hasta que publicó su Historia de las creencias y las ideas religiosas, en varios volúmenes que no pudo terminar en vida y de cuyo último tomo dejó solamente notas y esbozos. Resulta notable que la parte dedicada a la muerte, que vimos que había desgajado en su estancia portuguesa del libro, nunca terminase viendo la luz como la monografía definitiva que el autor hubiera querido diseñar. De hecho la Historia de las creencias es un trabajo bien diferente del que pensaba Eliade publicar como segunda parte del Tratado y del que habla a Álvarez de Miranda en su carta (aunque el autor lo tenía por tal, véase Turcanu 2003, 373).

69 El tema lo desarrolla Turcanu 2003, 356-357. 
(en rumano, la lengua en que escribía sus diarios) hubiera permitido obviar la crítica de Álvarez de Miranda y tantos otros y la incomodidad al respecto del propio Eliade.

Queda por revisar, en lo relativo a la relación con Eliade, un último episodio. La formación de discípulos quedó truncada para Álvarez de Miranda por la celeridad del desarrollo de su enfermedad, pero tuvo tiempo de intentar asegurar el inicio de la especialización de Ramón Valdés del Toro, que ya era licenciado por la Universidad de Valencia, estaba muy interesado por la historia de las religiones y se había acercado a él a partir de octubre de 1954 buscando orientación y le había visitado en diversas ocasiones en su casa y asistido a algunas de sus clases. También, en el verano de 1955 había actuado en la Universidad Menéndez Pelayo en Santander como secretario del curso de Humanidades y Problemas Contemporáneos del que era director Laín y subdirector Álvarez de Miranda. Valdés quería especializarse en religiones primitivas y desarrollar una tesis doctoral sobre el tema de la muerte en las religiones africanas y Álvarez de Miranda le aconsejó que fuese a estudiar a París con Mircea Eliade y envió una carta a Eliade, el 21 de octubre de 1955, escrita en español (como se puede suponer que también lo estaba la primera carta perdida), lengua que el rumano comprendía adecuadamente desde que la aprendió con la finalidad de poder leer a Marcelino Menéndez Pelayo ${ }^{70}$ y que empleó con frecuencia en sus años portugueses. Le dice en la parte dedicada a presentar a su discípulo:

[obtuve la] cátedra de Historia de las Religiones de la Universidad de Madrid. En ella menciono muchas veces su obra. Y en este aspecto me permito anunciarle la visita de un joven alumno mío, el Sr. Valdés, que irá dentro de pocas semanas a París a estudiar Historia de las Religiones y a trabajar en las Bibliotecas de esa ciudad. Para él será preciosa la enseñanza de Vd. en todos los aspectos.

Valdés en sus memorias recuerda el asunto. Expuso sus planes con cierto recelo (por temor a que los viese descabellados) a Álvarez de Miranda y le planteó que: «lo que ahora quería estudiar eran las religiones primitivas y a él le pareció muy bien. Enseguida me sugirió que entonces tendría que ir a Francia. Él le escribiría a Mircea Eliade para que me atendiera y me orientara». Más adelante cuenta el desenlace del episodio: "Cuando intenté contactar con Mircea Eliade, a quien mi maestro le había escrito, tuve una dolorosa sorpresa. Mircea Eliade se había marchado tiempo antes a Norteamérica, sin propósito de volver» ${ }^{71}$.

En este punto resulta interesante evidenciar que Álvarez de Miranda piensa para Valdés en Mircea Eliade y París y no en Italia y en un contexto de investigación y magisterio como el de Pettazzoni, que ese mismo año había organizado el Congreso Internacional de Historia de las Religiones. Es bien cierto que Pettazzoni no impartía ya docencia dado que estaba jubilado desde diciembre de 1953 y que su antigua cátedra en Roma estaba vacante, y también que Eliade era famoso por su monografía sobre el chamanismo que había publicado en 1951 y por las referencias etnográficas presentes en sus publicaciones. Pero la opción italiana podía haber tenido algunas ventajas ya que la etnología había sido uno de los intereses (y hasta

Diario Portugués, en la anotación del 10 de noviembre de 1941 (Eliade 2001b, 23; 2006, 110-111).

Valdés 2006, 2-6 y en comunicación personal. 
de la docencia ${ }^{72}$ ) del propio Pettazzoni y de alguno de sus alumnos, en particular de Vittorio Lanternari y que Roma en octubre de 1955 hubiera podido resultar un lugar de cierto interés, aunque desde luego no podía compararse con la Francia colonial de esa misma época. Es posible que Álvarez de Miranda pensase, además, que Eliade tenía asegurada una posición académica en Francia más sólida de lo que en realidad era, en su reseña antes comentada exponía sus puestos universitarios de modo incorrecto al decir que:

[...] el autor es un estudioso rumano bien conocido de los especialistas, al cual los azares de estos últimos años - pero sobre todo sus prestigiosos méritos científicoshan transplantado desde una cátedra en Bucarest a una cátedra de la École des Hautes Études, de París ${ }^{73}$.

Cuando llega Valdés a París Eliade ha emprendido su carrera americana, que será la que le permita alcanzar la verdadera estabilidad como académico y la posición de catedrático y de referente mundial de la disciplina.

En suma, esta opción por París para Valdés, que se podría llegar a juzgar como como una «pequeña traición» a la escuela pettazzoniana, sirve para ejemplificar y apuntalar del modo más claro que Eliade era el referente intelectual principal para Álvarez de Miranda, y también sirve de nexo de introducción con su otro gran referente, Raffaele Pettazzoni.

\section{El magisterio de Raffaele Pettazzoni}

Si Eliade era el futuro hacia el que lanzaba sus ojos Álvarez de Miranda, Pettazzoni era su referencia formativa y de presente, aunque con claroscuros y olvidos.

Frente a Eliade, que no aparece citado en la tesis italiana, Pettazzoni sí tiene cabida y es la primera vez que en la obra de Álvarez de Miranda hallamos al que será su maestro. Se refiere a su obra en dos contextos diferentes. Por una parte es citado en tres ocasiones, pero solo en notas, en la discusión respecto del papel del toro y la fertilidad en las religiones mistéricas. La cita, reiterada a lo largo de un párrafo de veinte líneas ${ }^{74}$, se refiere a la síntesis pettazzoniana titulada $I$ misteri ${ }^{75}$ que Álvarez de Miranda, además, tenía en su biblioteca privada y conocía con detalle, aunque veremos que no tendrá en cuenta de modo suficiente en su trabajo de cátedras que

72 Recordemos la Italia imperial de 1937 en la que Pettazzoni impartía los cursos de etnología histórica. Fue notable su participación en la Società di etnografía Italiana después de la guerra. Los trabajos de Pettazzoni dedicados a temas de religiones étnicas son muy numerosos como ilustra la recopilación de Gandini 2009, 179254 y Álvarez de Miranda los conocía bien, en especial los volúmenes que desde 1948 publicó titulados Miti e leggende, que comenzó con los dedicados a África y Australia (Pettazzoni 1948) y que le sirvieron de base, ya en Madrid y desde su posición de catedrático, para desarrollar algunos temas de la serie radiofónica que en 1955, entre febrero y abril, bajo el título «un mito cada semana» dedicó en algún caso a temas africanos (Mitos lunares de los bosquimanos) o australianos (Mitos australianos: la vuelta de las flores y la voz del dios), véase al respecto Díez de Velasco 2015, 90-91.

73 Álvarez de Miranda 1955c, 109. Hay que tener en cuenta que en ninguno de estos centros académicos Eliade ostentó una cátedra y que de hecho en Francia no era remunerado por su docencia ni contaba de forma estable con emolumentos (como expone Turcanu 2003, 345ss.; 354).

74 Álvarez de Miranda 2015, 141-142.

75 Pettazzoni 1924. 
versó justamente sobre las religiones mistéricas, y nos hallamos ante un asunto que requerirá más adelante un intento de explicación. Por otra parte Pettazzoni es traído a colación, y esta vez en el propio texto e incluyendo una frase suya entrecomillada, en el asunto, nada baladí, de la parte de realidad que se puede detectar en los mitos. La cita es la siguiente:

La idea de la «verdad» del mito es una conquista relativamente reciente de la conciencia histórico-religiosa. «La verdad de los mitos - ha escrito Pettazzoni- no es de orden lógico ni de orden histórico; es, sobre todo, de orden religioso y, más especialmente, mágico» ${ }^{76}$.

El argumento pettazzoniano a que se refiere aparece en la parte introductoria del primer volumen de lo que será la serie Miti e leggende ${ }^{77}$ y resulta una referencia de índole general, pero no circunstancial. En suma se puede plantear que Álvarez de Miranda tiene en cuenta a su maestro italiano en su tesis de un modo tan destacado como quizá lo permitía el carácter muy especializado de la temática taurina del trabajo. Y en cierto modo agradecía con las citas el apoyo e interés que por el tema pronto expresó Pettazzoni y que explicita Consuelo de la Gándara en el texto que apareció en la solapa de la edición de la traducción que promovió de la tesis de su marido y que se ha recogido como prólogo en la más reciente edición y en la que dice:

Al poco tiempo de llegar a Roma para estudiar Ciencias Histórico-Religiosas, empezó a rondar la mente de Ángel Álvarez de Miranda una idea que más tarde habría de convertirse casi en obsesión: interpretar a la luz de la Historia de las Religiones ese fenómeno tan español de las corridas de toros. Le animó mucho a ello el querido maestro Rafael Pettazzoni, que más tarde habría de ser ponente en la tesis que Álvarez de Miranda presentó en la Universidad de Roma con el título de Miti e riti del toro nel Mediterraneo ${ }^{78}$.

La siguiente cita aparece en el trabajo sobre la medicina del toro que redactó después de la tesis, y concluyó a finales de 1952. Se trata otra vez de una referencia en nota al libro I misteri en relación con la presencia del toro en el mitraísmo. El argumento lo expone en las siguientes palabras:

la sublimación de esta sacralidad del toro y de la virtud fecundante de su sangre, aparece, en el mitraísmo posterior, a través del rito del taurobolio [...] la sublimación se operó aquí transfiriendo al plano espiritual y soteriológico, característico de la religión mistérica, las virtudes materialmente fecundantes atribuidas a la sangre del toro, intuición característica de la religión naturalista ${ }^{79}$.

76 Álvarez de Miranda 2015, 155, en el original mecanografiado de la tesis (Álvarez de Miranda 1952a, 194) dice: «L'idea della "verità" del mito, è una conquista, relativamente recente, della scienza storico-religiosa: "La verità dei miti (ha scritto Pettazzoni) non è di ordine storico: è soprattutto di ordine religioso, e più specialmente magico"”.

77 Pettazzoni 1948, IX.

78 Consuelo de la Gándara en Álvarez de Miranda 1962; 2015, 9 (no se recoge en la reedición de 1998 o en la traducción de 2003).

79 Álvarez de Miranda 1959b, 21, nota 1. 
Así Pettazzoni le sirve para apuntalar, junto con Cumont, el aparato bibliográfico relativo al mitraísmo y el papel del toro en el ritual mistérico.

Las citas de Pettazzoni se diversifican algo más en «Poesía y religión». La primera se enmarca en un pasaje sobre la relación en las religiones antiguas de mito y rito y plantea que: «son dos expresiones paralelas -imaginativa la una, operativa la otra- de una idéntica experiencia sacral» y emplea como referencia bibliográfica el libro de Pettazzoni que recogía el curso que expuso en la Universidad de Roma en 1948-1949 al que probablemente asistió Álvarez de Miranda ${ }^{80}$. La siguiente cita está en la línea de las obras previas y es una referencia a I misteri en relación con la sacralidad del sacrificio de sangre ${ }^{81}$. El resto de las citas, que son dos, se refieren a la caracterización de la luna, tan presente en la obra de García Lorca sobre la que diserta, como un ser mortal: «así como yo muero... vosotros moriréis también», pero también superador de la muerte: «así como yo resucito, vosotros resucitaréis también». Aparecen en el texto (y no solo en notas bibliográficas) y se refieren al volumen primero de Miti y leggende ${ }^{82}$ que tanto interesó a Álvarez de Miranda.

La siguiente cita de Pettazzoni aparece en un trabajo en el que Álvarez de Miranda estudia a uno de sus referentes intelectuales clave, Ortega, asunto que revisaremos más adelante. No especifica la obra de Pettazzoni a la que se refiere, pero incluye en el texto su nombre, junto al de Jung, asociándolos a un modo orteguiano de enfrentar las cuestiones ${ }^{83}$, se trata de una actitud de compromiso intelectual que admira y que detecta en su maestro italiano.

También tiene cabida Pettazzoni, y en este caso uno de sus planteamientos de investigación que le dieron mayor fama y al que dedicó múltiples trabajos y una serie de monografías, el que enfocó al estudio de la confesión de los pecados en las diversas culturas a lo largo de la historia, en uno de los trabajos de Álvarez de Miranda más interesantes, el que dedica a la comparación entre las figuras de Job y de Prometeo. Para marcar la particularidad griega introduce un argumento de su maestro:

[...] se vislumbran aquí -como en tantos otros aspectos- radicales diferencias que separan el espíritu griego del oriental: no es un azar que la conciencia helénica constituya, como ha mostrado la vasta investigación de Pettazzoni, la única excepción a la práctica universal de la confesión de los pecados en la religiosidad del mundo antiguo y de los primitivos ${ }^{84}$.

Introduce dos referencias bibliográficas, el volumen tercero de la magna obra pettazzoniana sobre la cuestión ${ }^{85}$, que Álvarez de Miranda tenía en su biblioteca privada, tanto en la edición italiana (en sus tres volúmenes) como en la traducción

80 Pettazzoni 1949, en Álvarez de Miranda 1959b, 56, nota 1 se cita erróneamente como Lezioni di Mitologia (corregido en Álvarez de Miranda 2010, 41, nota 14), pero se trata de un error que quizá implique que quien cita las escuchó como lezioni.

81 Álvarez de Miranda 1959b, 70, nota 1; 2010, 62, nota 28.

82 Álvarez de Miranda 1959b, 79, nota 2; 2010, 78, nota 37; 1959b, 85, nota 1; 2010, 86 (sin referencia en nota).

83 Álvarez de Miranda 1953e, 7; 1959b, 381, la frase es la siguiente: «y, sobre todo, ocurre que a estas alturas, expresa o tácitamente, los muy diversos estudiosos acampados en asedio frente al hermético fenómeno de las mitologías - psicólogos como Jung, historiadores de las religiones como Pettazzoni-, ejercitan una poliorcética de signo orteguiano».

84 Álvarez de Miranda 1954b; 1959b, 254 y nota 4.

85 Pettazzoni 1936. 
francesa (que no incluye el tercero, que es el que le interesa pues trata de Grecia), y la referencia al tema en la recopilación de trabajos que publicó en 1946 y que también tenía en su biblioteca personal ${ }^{86}$.

De la misma época, es decir en los meses posteriores a la redacción y lectura de su tesis doctoral española y antes de la oposición a cátedras, son las dos citas que incluye en su artículo sobre la irreligiosidad polibiana. La segunda vuelve a referirse al libro de Pettazzoni que Álvarez de Miranda tiene como referencia clave, $I$ misteri, en una cita de aluvión ${ }^{87}$, pero la primera es muy significativa y ahonda en los temas clasificatorios que veremos que tanto le interesaban y que formarán la base de su trabajo de investigación para cátedras, que debía estar ultimando en la época en que redactaba este artículo. Apuntala el carácter de la religión griega como religión nacional, elemento fundamental para poder desarrollar su tesis respecto de la paradoxal irreligiosidad de Polibio, que no aceptaba las manifestaciones de impiedad que pudiesen ir en contra de la religión ancestral (en tanto que conformadora de la identidad nacional) mientras que en el plano personal era un descreído. Para ello su maestro italiano le ofrece dos referencias bibliográficas muy pertinentes, y en una nota las incluye exponiendo que son clave para reflexionar «sobre la trascendencia del concepto (de religión nacional) y del contenido de la "religión nacional" por oposición a las supranacionales y a las mistéricas ${ }^{88}$. Por tanto el esquema clasificatorio que usa Álvarez de Miranda y que será básico en su reivindicación del carácter específico de las religiones mistéricas, deriva directamente de Pettazzoni, aunque ahora veremos que no lo evidenciará en su trabajo monográfico dedicado al tema.

En efecto, octubre de 1953 fecha el preámbulo de su trabajo de cátedras, cuyo foco principal es la clasificación de las religiones mistéricas, lo que en el título nombra «el problema de su inserción en la historia general de las religiones». Fue publicado póstumamente, con pequeños retoques, en $1961^{89}$. Tiene cuatro capítulos muy desiguales en extensión, los dos primeros y el último son más teóricos y el tercero, que es el más extenso (casi triplica en páginas a los otros tres juntos), es un análisis de los diferentes misterios antiguos que incluye un aparato de citas bibliográficas muy detallado en el que la obra de Pettazzoni tiene cumplida cabida con más de una docena de $\operatorname{citas}^{90}$. De hecho el propio esquema del capítulo, dividido en subcapítulos dedicados a los misterios eleusinos, órfico-dionisiacos, cabíricos, mesenios, de Sabazio, de Atis y Cibele, de Adonis, de Isis y Osiris y de Mitra tiene un enorme parecido con el esquema del programa del último curso universitario de Pettazzoni,

86 Pettazzoni 1946.

87 Álvarez de Miranda 1959b, 411 nota 1 (con varios autores citados además de Pettazzoni).

88 Álvarez de Miranda 1959b, 383 nota 3, se refiere a Pettazzoni 1936-37, y a 1946, 153-168 (en italiano el capítulo se titula «Religioni nazionali, supernazionali e misteriche»).

89 Álvarez de Miranda 1961; algunos de estos cambios respecto del manuscrito que se conserva en el Archivo General de la Administración se repasan en Díez de Velasco 2007b, 111-112 nota 46.

90 Lógicamente la obra más citada es I misteri (Pettazzoni 1924, que tenía en su biblioteca privada) con siete referencias (en las notas 4, 37, 138, 164, 214 y 236), pero cita incluso la primera obra científica de su maestro (Pettazzoni 1908) que trataba de los cabiros (en la nota 68), y también muchas que tenía en su biblioteca privada, algunas que se habían publicado en los últimos años mientras prepara las cátedras, como la segunda edición de la religión griega (Pettazzoni 1953a, citada en la nota 36), la titulada Italia religiosa (Pettazzoni 1952a, citada en la nota 58), o las previas y que vimos que ya había utilizado en artículos anteriores como el volumen tercero de la confesión de los pecados (Pettazzoni 1936 citado en la nota 76), el libro recopilatorio de 1946 (Pettazzoni 1946, también citado en la nota 76) a las que se añade por último el libro de 1920 dedicado a Zaratustra (Pettazzoni 1920, citado en la nota 203). 
el de 1952-1953, que recopiló Angelo Brelich y se publicó en 195391, que era la época en que Álvarez de Miranda escribía este trabajo de cátedras y probablemente también asistía a las últimas clases de su maestro. También había citado a Pettazzoni en el capítulo segundo, dedicado a definir las características de religiones nacionales y lo que denomina su «decadencia» y «suplantación» por las mistéricas en dos ocasiones, pero no se refiere a las obras verdaderamente relevantes en relación con la tesis que defiende ${ }^{92}$. Tampoco lo cita en el capítulo cuarto pero es que se trata de una conclusión que carece de aparato de notas de bibliografía. En suma, las citas de su maestro en este trabajo eran numerosas alcanzando la quincena y se referían a casi una decena de libros o artículos, se podría decir que daba muy cumplida relevancia a Pettazzoni en esta obra, más que en ninguna de las anteriores.

Pero se produce un asunto poco explicable en el primer capítulo del trabajo, el que esboza un estado de la cuestión. Consta de tres partes, una primera que se titula «El problema historiográfico de las religiones mistéricas» y es una suerte de introducción corta sin aparato de citas en que se exponen los nombres diferentes que se ha dado a las religiones mistéricas y el plan de trabajo de la investigación. La segunda se nombra «Etapas y orientaciones relativas al estudio de las religiones mistéricas desde fines del siglo pasado hasta nuestros días» y en ella repasa rápidamente la bibliografía específica, citando tanto en el texto como en las notas las obras sobre religiones mistéricas de Otto Kern, de Carl Clemen, de Franz Cumont, de Hugo Hepding o de Hubert Reitzenstein, entre otras. Son trabajos de comienzos del siglo XX, pero algunos como el de Kern es de 1927, es decir, que no es solo una revisión de obras antiguas. No aparece citado un libro que hemos visto que tiene en su biblioteca personal, que se fecha en 1924 y que utiliza profusamente en otras ocasiones, y sobre todo, que resulta de inexcusable referencia en este punto para cualquiera, y en especial para alguien formado en Roma: I misteri de Pettazzoni. La tercera parte del capítulo primero, que denomina «Las religiones mistéricas en la Historia General de las Religiones: reseña y crítica de su inserción» repasa el papel que tienen las religiones mistéricas en los trabajos generales de historia de las religiones, repasando, entre muchos otros, a Salomón Reinach, a Pietro Tacchi-Venturi, a Gustav Mensching, a Nicola Turchi, vimos que a Mircea Eliade, a Gerardus van der Leeuw, a Franz König y hasta al padre Wilhelm Schmidt, aunque en una cita forzada, puesto que se está realmente refiriendo a la obra del anterior en la que Schmidt solo es prologuista. Pero no aparece ni una mención a Pettazzoni, máxime cuando lo que exponen todos estos autores no le convence ya que no ofrecen una correcta clasificación de las religiones mistéricas que en sus propias palabras:

florecen precisamente en el momento de decadencia de la religión nacional. Son su sustituto y las reemplazan definitivamente. Históricamente, por lo tanto, las religiones mistéricas ocupan en el desarrollo cronológico del mundo antiguo un lugar posterior a las nacionales y anterior a las universales ${ }^{93}$.

\footnotetext{
91 Pettazzoni 1953b, las característica del curso las revisa Gandini 2007a, 43-44.

92 Se trata de los trabajos sobre el sintoísmo en tanto que religión nacional del Japón (Pettazzoni 1931b, que cita en la nota última de este capítulo; además el tema que presentó como lección magistral de cátedras fue justamente sobre las religiones de Japón y el sintoísmo, asunto que se revisa en Díez de Velasco 2007b, 105) y de la religión augustea (Pettazzoni 1938 que cita en la nota 25).

93 Es el párrafo final del capítulo, en la edición póstuma: Álvarez de Miranda 1961, 18.
} 
Hemos visto que el análisis que clasifica las religiones en nacionales, mistéricas y supranacionales lo desarrolló Pettazzoni tiempo atrás y Álvarez de Miranda lo conoce y lo ha citado en su artículo, ya revisado, sobre Polibio ${ }^{94}$. Estaba escribiendo este trabajo de cátedras en el entorno de la fecha en que desarrollaba la discusión sobre la religión nacional en su artículo sobre la irreligiosidad polibiana, y estaríamos en el otoño de 1953. Parece bastante probable que debió de cambiar la redacción y renunció a citar a su maestro en una posición relevante en el capítulo primero de su trabajo de cátedras por alguna razón que quizá pueda intuirse gracias a la revisión de su correspondencia.

En la carta a Santiago Montero que ya hemos citado anteriormente, fechada el 8 de octubre de 1952, que inaugura la correspondencia entre ambos, expone lo siguiente:

Hace más de tres años que estoy en Italia y que no le veo, y quiero darle cuenta, ante todo, de que en este tiempo he cursado íntegramente en la universidad de Roma la carrera de Letras en la Sección de Historia de las Religiones. En todas las materias he obtenido la calificación máxima incluso en la tesis doctoral que bajo la dirección del prof. Pettazzoni he hecho sobre «Mitos y ritos del toro en las religiones antiguas» [...] He tenido la fortuna de encontrar aquí a Pettazzoni: no solo es presidente de la International Association for the Study of the History of Religions, y está considerado como el más grande cultivador actual de esta disciplina, sino que además me ha profesado un gran afecto y tiene no pocas esperanzas en mí $[\ldots]$

El contexto de la carta tiene que ver con que Álvarez de Miranda intenta que Montero retome la dirección de su tesis española, que es imprescindible tener leída para opositar a cátedras, y quiere redefinir en lo posible dicha tesis en consonancia con su dedicación en Italia a la historia de las religiones. Envió otra carta el 1 de noviembre, volviendo a insistir en el tema, pero ante la falta de contestación recurre a Laín, que contacta con Montero y el 25 de febrero de 1953 Montero contesta favorablemente en el asunto de la tesis y expresa su entusiasmo por la disciplina, pero plantea ciertas puntualizaciones que parecen un aviso a navegantes:

Conozco la personalidad de Pettazzoni, y me llena de alegría que al fin tengamos en España un especialista en Historia de las Religiones con la formación de Ud. Digo con la formación de Ud. porque los historiadores de las religiones suelen moverse exclusivamente o en el plano de una controversia dogmática, desde puntos de vista cerrados; o en el recinto más estrecho aún de una antropología naturalista y cotejos etnográficos muchas veces fantásticos. Ud. aportará un saber clasicista de primer orden y una posición humanista, histórico-cultural. Estoy, pues, auténticamente encantado $[\ldots]$

Solo indica, casi de pasada, una referencia a Pettazzoni, pero matiza acto seguido que es la formación clásica de Álvarez de Miranda lo que se necesita, no los «cotejos etnográficos» o la «controversia dogmática». Seguramente con controversia dogmática se estaba refiriendo al posicionamiento pettazzoniano en relación a la tesis del

94 Son Pettazzoni 1936-37 y 1946, 153-168. 
Urmonotheismus de Wilhelm Schmidt, que no podemos olvidar que era el gran referente en el estudio de las religiones para el pensamiento español del momento y cuyo manual de historia comparada de las religiones del españolizado como "padre Guillermo Schmidt» había sido traducido en 1932 y había tenido una segunda edición en $1941^{95}$. Se trataba de un sabio católico, sacerdote, cabeza de una escuela, la de Viena, intachable desde el punto de vista del magisterio de la Iglesia, en cuyo contexto de trabajo, además, en esos años (1951) se había publicado de la mano de Franz König, poco después nombrado cardenal, y con la colaboración de un elenco de discípulos de Schmidt, como ya adelantamos, y con prólogo suyo, un afamado manual de Historia de las religiones que portaba el simbólico título de Christus und die Religionen der Erde. Se trata de un libro que Álvarez de Miranda tenía en su biblioteca y al que dedicó en su primera lección de cátedras una referencia indirecta, por medio de una cita a Dominik Wölffel, el «discípulo» de Schmidt que mayor relación había tenido con España y en especial con Canarias ${ }^{96}$. La mirada de Álvarez de Miranda ya hemos visto que sí se posa en Schmidt, y de un modo forzado, en su trabajo de cátedras que estamos revisando, al tratar del estado de la cuestión sobre las religiones mistéricas, pero no así en un Pettazzoni cuyo trabajo al que nos estamos refiriendo, titulado Dio. Formazione e sviluppo del monoteismo nella storia delle religioni, vol. I: L'essere celeste nelle credenze dei popoli primitivi, que Álvarez de Miranda tenía en su biblioteca privada, parece que podía enjuiciarse como que añadía a la controversia también esos cotejos etnográficos contra los que Montero parece que prevenía a su doctorando ${ }^{97}$. También es posible que Montero, además, interesado por los temas de mitología, conociese de Pettazzoni su Miti e leggende, que recordemos que centraba su primer volumen en señeros territorios del cotejo etnográfico (África y Australia), bien lejos del encuadramiento en los límites del saber clasicista que reivindica en y para su discípulo en su carta.

Pero aún más clara es aún la posición de Montero en su carta del 30 de octubre de 1953, la fecha justo en que Álvarez de Miranda está ultimando su trabajo de cátedras:

Creo que tiene Ud. en Pettazzoni un buen consejero y amigo. No obstante, a mí me gustaría haber hablado algo con Ud. sobre la memoria y ciertos enfoques. Algunos problemas de metodología, a mi juicio, quedan por completo fuera de la órbita doctrinal en que se mueve Pettazzoni.

Montero entiende que la perspectiva pettazzoniana resulta limitada, quizá porque por su formación alemana estimaba que la Historia de las Religiones acotaba la «órbita doctrinal» de una disciplina cuyo mayor calado se vislumbraba mejor desde la atalaya de una Ciencia de la Religión que tenía también en cuenta el Sentido (con mayúscula) que podía aportar la metodología y el enfoque de la Filosofía, cuestiones que parece que pensaba que Pettazzoni, con un rotundo «por completo», era incapaz de tener en cuenta. En suma, Montero no pensaba que Pettazzoni fuese un referente

\footnotetext{
Schmidt 1932.

Véase Díez de Velasco 2017b, tratando la referencia al trabajo de Dominik Josef Wölffel incluido en ese manual.

97 De entre una multitud de citas posibles relativas al enfrentamiento de Pettazzoni con Schmidt a cuenta del $U r$ monotheismus, resultan muy esclarecedoras y significativas (también por escribirlas un monje benedictino) las páginas de Lluís Duch 1997, 97-99.
} 
intelectual verdaderamente adecuado, no lo consideraba una figura de primer orden ${ }^{98}$, y este juicio pudo influir en el Álvarez de Miranda que preparaba la oposición, que necesitaba firmes defensores y que sabía que Montero quería estar en ese tribunal desde que le expresó esa voluntad en una carta del 16 de marzo de 1953 en la que planteaba que insistiría ante el Ministerio de Educación (como efectivamente hizo) en su derecho a ser miembro ${ }^{99}$. La cátedra se convocó en agosto de 1953, en enero de 1954 Álvarez de Miranda ya sabía que tenía dos contrincantes y en abril conocía el tribunal que lo juzgaría, en el que había dos eclesiásticos en el titular (un jesuita y un dominico) y tres en el suplente (un jesuita, un agustino y un benedictino) ${ }^{100} \mathrm{y}$ en el que, efectivamente, se incluía a Montero. Por otra parte, en febrero de 1954 el padre Guillermo Schmidt había fallecido y su figura había cobrado en esos meses nueva relevancia y poblaba el recuerdo vivo de algunos intelectuales católicos españoles. Pettazzoni y su modo de enfrentar el estudio de las religiones podía ser visto como problemático para ciertos miembros de la iglesia, tanto en Italia como en España, y recordemos que uno de los miembros titulares del tribunal, el padre García Villoslada, era profesor de la Gregoriana de Roma y estaba al tanto de estas cuestiones, aunque es bien cierto que era favorable a Álvarez de Miranda, al que conocía de su paso por su universidad. Por su lado Pettazzoni en estas fechas, aunque rozando la jubilación o ya jubilado, gozaba de destacada notoriedad en Roma más allá de los ámbitos puramente académicos ya que se encontraba plenamente implicado en la preparación del VIII Congreso de Historia de las Religiones, que era la primera vez que se planteaba desarrollar en un país del sur de Europa y con tanto peso del componente católico como Italia y además en una ciudad con tal peso simbólico como era Roma y lo hacía no sin tener que enfrentar voces discordantes ${ }^{101}$. Y aunque hay testificaciones documentales de que Pettazzoni pensó en Álvarez de Miranda para tener algún tipo de implicación en el congreso ${ }^{102}$, ésta no se materializó quizá porque el discípulo se vio impelido a apartarse en alguna medida de su maestro italiano para no evidenciarse ante su maestro español y ante quienes tenían que abrirle paso y acogerlo en la universidad española donde, desde luego, tenían al padre Schmidt en mucha mayor estima que a alguien que le hubiese enfrentado en un debate en el que los argumentos científicos y de índole metodológica eran solo una parte de una ecuación en la que los argumentos de fe tenían un peso insoslayable para esos lectores

98 Así lo recordaba en una entrevista personal (realizada el 13/04/2007) José María Blázquez, que hay que tener en cuenta que en esta fecha (1953) estaba en Roma estudiando y tenía relación con Álvarez de Miranda y con Montero. Tampoco podemos obviar la adscripción política pettazzoniana que si se conocía en España podía no ser del gusto del Montero de esta época ni de algunos otros miembros del tribunal de cátedras.

99 En efecto lo hizo en una carta fechada el 20 de diciembre de 1953 dirigida al entonces Director General de Enseñanza Universitaria, Joaquín Pérez Villanueva (véase Díez de Velasco 2007b, 98ss. para todo este asunto).

100 Ricardo García Villoslada era jesuita, y Alberto Colunga, dominico, aunque terminó renunciando y fue sustituido por el suplente Justo Pérez de Urbel que era benedictino; los otros dos suplentes eclesiásticos que no actuaron fueron el presidente suplente, José Marín Bover, que era jesuita y el vocal, Ángel Custodio Vega, que era agustino.

101 Véase Pettazzoni 1952b, y el trasfondo que sus palabras implican. En una entrevista personal en marzo de 1994, Jean Pierre Vernant recordaba cómo Pettazzoni comentaba el rechazo que encontró entre algunos responsables católicos influyentes a que se le permitiese hacer en Roma un congreso que trataba de otras religiones más allá del catolicismo.

102 Pettazzoni anotó el nombre de Álvarez de Miranda como uno de los posibles invitados al congreso de Roma que sirvieran de representación de los países sin implantación académica de la Historia de las Religiones en la reunión en París en mayo de 1953 del comité ejecutivo de la International Association for the Study of the History of Religions (Gandini 2007a, 39; 2007b, 70). 
españoles. Volveremos un poco más adelante a revisar con mayor detalle a Wilhelm Schmidt como referente intelectual de Álvarez de Miranda, pero este ambiente quizá sirva para explicar un asunto que Mario Gandini ${ }^{103}$, en su concienzuda biografía de Pettazzoni, no podía dejar de destacar. Y es que Álvarez de Miranda en su primera lección de cátedras de octubre de 1954, es decir en su puesta de largo ante el claustro universitario al que acababa de entrar a formar parte dos meses antes, no cita a Raffaele Pettazzoni. Hemos visto que cita a Eliade, que por medio de Wölffel hace un guiño a la Escuela de Viena, veremos más adelante que reitera varias veces la importancia que otorga a Menéndez Pelayo, pero nada indica de modo explícito que se haya formado bajo la tutela del fundador de la llamada «Scuola di Roma», aunque muchos presupuestos del método histórico-religioso italiano permeen implícitamente la perspectiva que expone en su lección ${ }^{104}$.

Hay dos citas más de Pettazzoni en la obra posterior de Álvarez de Miranda. Por una parte encontramos una referencia sin ubicación bibliográfica precisa y en la que Pettazzoni se une a diversos otros autores en una cita en aluvión, que se incluye en un trabajo derivado en parte de su tesis italiana que el recién nombrado catedrático publica en la revista de su universidad y que lleva el título programático de «Cuestiones de mitología peninsular ibérica» y donde se refiere a su maestro en el contexto del repaso a las relaciones entre rito y mito ${ }^{105}$. La segunda es de mayor calado puesto que, por una parte, se fecha ya en 1955, en la primavera, y ahora veremos que a comienzos de mayo Álvarez de Miranda recobrará su relación, en este caso ya solamente epistolar, con Pettazzoni, y por otra, es el primer trabajo en el que el nuevo, pero ya consolidado catedrático de la materia, se aventura a tocar uno de los temas más escabrosos de la disciplina, como es el de sacrificio sangriento que se materializa incluso en sacrificio humano. En cierto momento de su análisis, en el que intenta ofrecer instrumentos que permitan ir más allá de la mera descalificación del rito en sí y de la sociedad que lo puso en práctica, se adentra en la comparación y acude a su maestro: «Ya Pettazzoni puso de relieve, en su vasta investigación acerca de las prácticas penitenciales en las religiones no cristianas, la existencia en Méjico y Centroamérica del rito de la extracción de sangre» ${ }^{106}$. No desarrolla la cita bibliográfica, pero se está refiriendo principalmente al primer volumen del magno trabajo sobre la confesión de los pecados que vimos que Álvarez de Miranda tenía en su biblioteca privada tanto en la edición italiana como en la traducción francesa ${ }^{107}$.

En la semana del 17 al 23 de abril de 1955 se desarrolló el Congreso en Roma ${ }^{108}$ que resultó un éxito, asistieron varios españoles, Francisco Cantera Burgos, Alberto Balil, Martín Almagro o Miquel Tarradell, la imagen de Pettazzoni quedó claramente fortalecida, y en ese contexto encontramos que Ángel Álvarez de Miranda envía una carta a su maestro una semana después, fechada el 7 de mayo, en la que se excusa de no haber podido asistir al congreso romano del que dice que ha tenido muchas noticias confirmando que ha sido un «grande succeso». Le dice que está paralítico, que tiene que desplazarse en silla de ruedas y utilizar un dictáfono ya que no puede escri-

\footnotetext{
103 Gandini 2006b, 117.

104 Véase Díez de Velasco 2015, 244-245; 2017b, apartado 2.

105 Álvarez de Miranda 1959b, 191.

106 Álvarez de Miranda 1959b, 338.

107 Pettazzoni 1929; 1931a.

108 Gandini 2007b, 156-166.
} 
bir, que no puede viajar, pero que ha ganado la cátedra de Historia de las Religiones en la Universidad de Madrid y que tiene planes en los que quisiera que Pettazzoni tuviese un papel principal. Sus palabras son:

Se abre la posibilidad de que se cree en nuestro Consejo de Investigaciones una sección de Historia de las Religiones que yo dirigiría. Tengo una gran ilusión de poder organizar, quizá el año próximo, encuentros científicos que me abran la oportunidad de invitarle a impartir alguna conferencia en Madrid. Desde luego en mi intención está que sea Ud. el primer estudioso extranjero que venga a inaugurar en España el nacimiento oficial de estos estudios [...] Espero poder tener con Usted muchos contactos que serán muy fructíferos para el destino de la Historia de las Religiones. Hoy me limito a hacerle llegar mis más cordiales saludos. Su devoto alumno y amigo.

Pero más significativo aún es el párrafo segundo de su carta en el que expresa del modo más elocuente su gratitud hacia el maestro:

Tuve que encarar, en los primeros meses del año 1954, los trabajos científicos para la oposición que me ha llevado a ser catedrático de Historia de las Religiones en la Universidad de Madrid [...] Verdaderamente ha sido un triunfo el obtenido en la Universidad y lo atribuyo a las inapreciables enseñanzas recibidas de Ud. en Roma. Ojalá todos fuesen como yo, alumnos del Profesor Pettazzoni, porque yo, por mi parte, me he gloriado de este hecho, y pienso que, poco a poco, la Historia de las Religiones alcanzará en España la consideración científica que merece. Imparto las lecciones en la Universidad y pienso que con algún éxito ${ }^{109}$.

Parece que Álvarez de Miranda, a pesar de su enfermedad, piensa que podrá conseguir que se consolide tanto la faceta docente como investigadora de la disciplina, y una vez liberado de las ataduras del clima paranoico característico de las oposiciones a cátedras de aquellos años, va a poder desarrollar su madurez plena como historiador de las religiones, y coincide con la forma en que su maestro italiano entiende la disciplina, pues convergen, por ejemplo, en la mutua admiración por Eliade y sus modos de trabajo. Y a ese relato de su éxito académico quiere asociar a un Pettazzoni de cuyo éxito internacional han llegado noticias a la universidad española. Pettazzoni contesta a vuelta de correo el 18 de mayo con un papel con el membrete del VIII Congresso Internazionale di Storia delle Religioni, se muestra conmovido por la enfermedad y feliz de que la cátedra resulte un «alto reconocimiento oficial de su excelente calidad como estudioso y a la vez la magna carta de la introducción de la Historia de las Religiones en la Universidad española» y emplaza a su discípulo a volver a verse pronto en Madrid. En otra carta más de un año posterior (del 22 de junio de 1956) expresa del modo más claro su afecto y le dice que le recuerdan en Roma en las reuniones del Istituto di Studi Storico-religiosi de la Universidad de Roma (con cuyo membrete se encabeza el papel de la carta que le envía). Pero en ese momento ya Álvarez de Miranda estaba completamente

109 Sigo en ambas citas el texto italiano de la carta que publicó Gandini 2006b, 118 con las correcciones ortográficas pertinentes. 
impedido y no pudo ni continuar con sus publicaciones ni seguir con la docencia, que solo llegó a poder desarrollar en el curso 1954-1955. Caso contrario, la reivindicación de su maestro Pettazzoni que expone en su correspondencia se hubiera plasmado de modo bien claro en sus publicaciones. Y desde luego su trabajo de cátedras, que vio la luz en 1961, casi cinco años después de su muerte, hubiera otorgado a Pettazzoni el lugar que le correspondía en el estado de la cuestión sobre el tema. Pero el libro apareció con un título recortado que prometía más de lo que contenía, ya que Álvarez de Miranda no pudo adaptar personalmente un trabajo de circunstancias y pensado para ser leído solo por cinco personas, para convertirlo en una monografía de impacto general.

\section{Otros referentes intelectuales}

Tras revisar a su maestro italiano y el impacto que tuvo en su pensamiento resulta lógico lanzar la mirada hacia su maestro en España, Santiago Montero Díaz. Se trataba de un profesor fascinante, con una formación muy sólida y unas lecturas muy variadas. Interesado por multitud de temas, no desdeñaba los mundos no europeos y también las miradas hacia el continente asiático. Y tenía un particular interés por el estudio de las religiones, que se plasmó de modo muy claro en la defensa del mantenimiento en su universidad de la enseñanza de Historia de las Religiones que hizo a la muerte de Álvarez de Miranda, de cuya docencia se encargó desde que resultó evidente que su discípulo había quedado impedido para hacerlo, a partir del curso 1956-57, y que mantuvo a lo largo de los años (con algunas interrupciones), ofreciendo incluso cursos de doctorado en la materia como el de "Introducción a la metodología de la Historia de las Religiones». En la época en que Álvarez de Miranda preparaba las oposiciones le aconsejó y ayudó en diferentes momentos. Hemos visto que en la carta del 30 de octubre de 1953 decía Montero que hubiera querido trabajar con él ciertos conceptos de su memoria de cátedras ya que pensaba que había aspectos en los que la ayuda de Pettazzoni era insuficiente dada su orientación metodológica y teórica. Esa ayuda y supervisión se produjo en reseñable medida durante la estancia que tuvo Montero en Roma, invitado a dictar una conferencia en el Instituto que dirigía Álvarez de Miranda en abril de 1954. En efecto, en la correspondencia posterior (una carta del 5 de mayo de 1954 de Montero, con contestación del 10 de mayo de su discípulo) exponen que hablaron entonces de temas de fondo relativos a la oposición. Hasta podríamos especular que se produjo en este momento el antes reseñado cambio en los capítulos introductorios de su trabajo sobre las religiones mistéricas que apartó a Pettazzoni de las citas en la revisión del estado de la cuestión. Montero incluso se llevó la copia final mecanografiada de «Poesía y Religión» para revisarla y se la devolvió ya en Madrid expresándole que le parecía un excelente trabajo. La última carta de Montero se fecha el 4 de julio, casi en vísperas del desarrollo del primer ejercicio (que empezó el 6) y se trata de un largo envío de una decena de páginas en el que ofrece puntualizaciones y bibliografía para que Álvarez de Miranda las use, relativas principalmente a temas de religión china (tres densas páginas), y sobre Isis y Dea Caelestis. Vemos, por tanto, que Montero se implicó en el proceso de oposición de su discípulo, no solo en cuestiones administrativas y burocráticas, sino también de índole plenamente científica. Por su parte Álvarez de Miranda no cita a Montero en sus escritos más que en dos 
ocasiones y ambas en su primer artículo de entidad, que escribió en 1945, y que dedicó a Tucídides, y no se relacionan con ninguna referencia de carácter religioso ni mitológico ${ }^{110}$. Era la época en la que empezaba a plantearse redactar una tesis doctoral y Montero fue un referente con el que ya en 1946 contó como director a la hora de inscribir su tesis. Bien es verdad que Montero, que era reconocido como un profesor de una calidad extraordinaria, que tenía una ambición generalista que no se arredraba ante el uso del método comparado, y que dirigió un número notable de tesis y tesinas, muchas de ellas de temas religiosos variados, incluso antes que la del propio Álvarez de Miranda ${ }^{111}$, no fue un autor prolífico ${ }^{112}$, y el único trabajo que el Álvarez de Miranda historiador de las religiones hubiera debido de haber citado fue el que dedicó, además en Cuadernos Hispanoamericanos, al mito de Quetzalcóatl $^{113}$, donde desarrolla un análisis de historia de las religiones bien documentado, pero que Álvarez de Miranda no tuvo en cuenta en su trabajo, ya repasado, de 1955 sobre Méjico y el sacrificio cruento, también publicado en la misma revista y donde, además, se refiere a Quetzalcóatl en cuatro ocasiones. Es verdad que en ese trabajo Álvarez de Miranda no incluye ninguna cita con bibliografía detallada sino que se limita a nombrar autores en genérico, sin ubicar la publicación de modo exhaustivo. Pero no es menos cierto que si que citó a Pettazzoni, como acabamos de ver. Este olvido del maestro español en 1955 a la par que vuelve a reivindicar al italiano previamente olvidado por influjo del primero, quizá apuntale la idea de que el catedrático Álvarez de Miranda, desde su ya sólida posición como única cabeza de la disciplina en la Universidad Central de Madrid y en toda España, redimensionaba sus deudas y delimitaba sus referentes intelectuales, prefiriendo a Pettazzoni, con quien hemos visto que reanuda la correspondencia, frente a Montero, con quien, quizá también por compartir claustro, no volverá a contactar por carta y perdemos por tanto esa vía de información.

Otro de los personajes clave en la vida y el éxito académico de Ángel Álvarez de Miranda fue Pedro Laín Entralgo, al que ya había dedicado en 1948 una nota panegírica ${ }^{114}$ en la revista Alférez que evidenciaba una amistad luego correspondida en no menos elogiosos y amistosos prólogos por Laín ${ }^{115}$ tras su muerte. Álvarez de Miranda citó trabajos suyos en otras dos ocasiones en sus primeros escritos al tratar temas no relacionados con lo religioso, resaltando la agudeza de su caracterización de la generación del $98^{116}$. Pero la cita más significativa, por incluirse en un trabajo de análisis histórico-religioso de Álvarez de Miranda, es la larga doble referencia que aparece en «Poesía y religión» que además parece que resultó determinante a la hora de terminar titulando póstumamente la obra como La metáfora y el mito. Jus-

110 Álvarez de Miranda 1959b, 16 nota 1 y 21 nota 1, citando a Montero 1943.

111 En 1947 dirigió la de Gustavo Bueno Martínez, titulada «Fundamento formal y material de la moderna filosofía de la religión»; en 1948 la de Saturnino Casas Blanco, «Demostración de la existencia de Dios en la filosofía de Don Ángel Amor Ruibal»; en 1950 la de Salvador Mañero Mañero, «Dios en concepción aristotélica del universo» o en 1953 la de María Teresa Socorro Santiago, «La influencia del pensamiento hindú en las literaturas de lengua española», posteriormente dirigió muchas más.

112 Su bibliografía la estableció en primer lugar su hijo (Montero 1989) en el volumen de homenaje que se dedicó a su padre en la revista Gerión de la que había sido el primer director, y también la recopila Antonio Duplá en Montero 2004, LXXXV-XC. Más bibliografía dedicada a Montero en Díez de Velasco 2015, 104-105, nota 59.

113 Montero 1950.

114 Álvarez de Miranda 1948h.

115 Laín 1959; 1961.

116 Álvarez de Miranda 1948i, 94; 1950b, 55 (1959a, 316). 
tamente el único momento en el que en el trabajo se usa la palabra metáfora es en la siguiente cita:

La importancia deriva de haberse planteado Laín el alto problema de cuáles son los diversos modos de saber acerca de la realidad, y en especial el modo del saber poético, que se ejercita a través del sutil mecanismo de la metáfora; y más concretamente en el hecho de que Laín percibe a Lorca como un caso prototípico del conocimiento poético de índole preferentemente sensorial. Dice Laín: «La poesía de orden sensorial y metafórico - tal la de García Lorca- contiene a la realidad según la plenitud de las significaciones que la apariencia sensible de esa universal realidad puede ofrecer al espíritu humano» ${ }^{117}$. Estas palabras contienen el germen de lo que aquí estamos verificando: esa «plenitud de las significaciones» lo es hasta el punto de contener en sí las de estirpe y cariz religioso. ${ }^{118}$

El análisis de Laín, con ese enfoque que nos resulta tan moderno (hoy diríamos plenamente entroncado en una antropología de la sensorialidad), entronca con una figura que forma una referencia mutua de fondo en ambos, Ortega, del que luego se tratará con un poco más de detalle. Unas líneas más adelante, en la nota siguiente, Álvarez de Miranda vuelve a citar la misma obra de Laín en lo relativo a un tema que podríamos denominar también como muy vanguardista para el momento, como era la referencia a Carl Gustav Jung y sus arquetipos, aunque ya hemos visto como el pensamiento junguiano, sin que Álvarez de Miranda comulgue con él (asunto que por otra parte aproxima su punto de vista al de Eliade ${ }^{119}$ ), estaba presente en este trabajo y en el subtítulo que hubiera querido haberle dado, de «Descenso al antro de García Lorca». Las palabras de Álvarez de Miranda en este asunto de Laín son las siguientes:

En el estudio citado [...] se remonta Laín, a través del tema de la serpiente, a la teoría junguiana de los arquetipos o figuraciones genéricas del inconsciente colectivo. Este sugestivo problema psicológico queda deliberadamente omitido en nuestro estudio para no salirnos de los límites de lo histórico-religioso. Dentro de estos límites, sin embargo, no será ocioso recordar que la serpiente es el animal dotado de valores religiosos más polivalentes y complejos. ${ }^{120}$

Ya hemos visto que «Poesía y religión» se presentó en dos versiones a la oposición, una corta y ya publicada y una larga e inédita que vería la luz póstumamente incluso como monografía. Hay que recordar que Laín en 1954 era rector de la Universidad Central de Madrid y que, además, era el presidente del tribunal de la cátedra de Historia de las Religiones a la que aspiraba Álvarez de Miranda. Se trata tanto de un guiño al presidente y rector como de una clara asunción del débito intelectual. Laín había tratado sobre García Lorca, podríamos incluso decir que se había atrevido a hacerlo en la España de aquel entonces. Álvarez de Miranda seguía sus pasos y se aventuraba a aplicar de modo sistemático el análisis histórico-religioso y

\footnotetext{
117 Incluye aquí la referencia a las páginas (9-10) de la obra que cita de Laín (1952).

118 Álvarez de Miranda 1959b, 60 nota 1; 2010, 130 nota 20.

119 Asunto desarrollado con detalle en Díez de Velasco 2009, 268-277.

120 Álvarez de Miranda 1959b, 61 nota 1; 2010, 131 nota 21.
} 
la comparación a ese gran poeta que ambos reivindicaban, por tanto, explícitamente. Parece claro que Laín, a pesar de no tener el estudio de las religiones como su foco principal, resultaba un referente intelectual destacado en cuyos análisis intenta profundizar Álvarez de Miranda en este trabajo que es quizá el más sugerente y en el que evidencia del modo más claro las potencialidades interpretativas y explicativas de la disciplina que cultivaba.

Volviendo a su primera lección como catedrático, ya hemos visto como citó a Eliade pero calló la mención de Pettazzoni. Pero hay que tener en cuenta que se trataba de un trabajo que cumplió en cierto modo el papel de un manifiesto, por tanto resulta muy significativo que su autor más citado, en cuatro ocasiones, haya sido Marcelino Menéndez Pelayo. Era en la España y la universidad de aquel momento un referente ideológico insoslayable y citarlo era un modo de alcanzar el beneplácito general. Pero también hay que tener en cuenta que la Historia de los heterodoxos españoles era lo más cercano al empeño que tenía ante sí Álvarez de Miranda cuando quería trabajar sobre las religiones en España ${ }^{121}$. Pero Álvarez de Miranda si bien reivindica hábilmente a Menéndez Pelayo como un precursor, no deja de evidenciar lo que le separa de él, y para ello no duda en incluir largas citas del autor en su trabajo. La primera cita se enmarca en la justificación de su planteamiento del interés que tiene la recién estrenada disciplina en el panorama de la ciencia española, y sus palabras son bien claras:

Ya Menéndez Pelayo vislumbró, en los últimos años de su vida, la importancia que podrían tener las viejas estructuras del pensar mítico precristiano en relación con el desarrollo histórico-religioso de la vida española. Y así en la reedición de los «Heterodoxos», al dedicar un volumen entero a lo que en la edición primitiva había despachado en cuatro páginas, esto es, el cuadro de la religiosidad precristiana, dió principio a su tarea con estas palabras: «La historia de las creencias religiosas profesadas en España antes del cristianismo es peculiar e indispensable a la historia de los heterodoxos españoles. En estos cultos primitivos, indígenas o importados, está acaso la explicación de algunos fenómenos que durante el curso de los siglos se repiten en nuestras sectas heréticas y son o pueden ser una prolongación atávica... Aquilatar el influjo y persistencia de estos elementos no es materia ajena del historiador eclesiástico... Esta materia puede dar ocupación provechosa a la vida de un hombre y un cúmulo de conocimientos especiales, puesto que sus fuentes no pueden ser más diversas. Mucho deseamos que algún erudito... se decida a recoger sistemáticamente el material que poseemos y a interpretar los hechos conforme a los positivos resultados que va logrando, merced a los progresos de la lingüística y la arqueología, la Ciencia de las Religiones o Mitología Comparada». Dejando de lado, en estas palabras de Menéndez Pelayo, la discutible conexión que tiende a establecer entre religiosidad primitiva y heterodoxia, es indudable en todo caso que el gran historiador presintió y palpó más que nadie en su época la conveniencia de vitalizar la comprensión de nuestra cultura desde el saber histórico-religioso. No es éste el lugar adecuado para examinar hasta qué punto se han realizado las desiderativas palabras de Menéndez Pelayo. En todo

121 A pesar de no poder tratarse de un trabajo de historia de las religiones por evidentes razones de índole teórica y metodológica, dado que el religiocentrismo de Menéndez Pelayo le alejaba de los presupuestos de base de la disciplina, véase Díez de Velasco 2012. 
caso, es indudable que los fenómenos histórico-religiosos de la cultura española polarizan el creciente interés de muchos estudiosos $[\ldots]^{122}$.

La segunda cita, ya casi al final de su lección, es aún más interesante, pues no es que ponga en duda como en el caso anterior la pertinencia de la relación del panorama precristiano con el posterior hecha por Menéndez Pelayo, sino que rechaza el propio concepto de heterodoxo/ortodoxo, desde luego en pura lógica metodológica, pero enfrentando seguramente a muchos que podían reivindicar esa posición combativa de carácter puramente teológico. Está apuntalando su nueva mirada que encuentra en lo sagrado una mejor herramienta (que además aproxima su perspectiva a un Mircea Eliade que ha citado anteriormente) y que aparta su perspectiva de las maneras de trabajo de la teología. El pasaje es el siguiente:

[...] energía sacralizadora [...] que por sí misma cae bajo la demarcación de la «Historia de las Religiones» como ciencia que opera desde una específica sensibilidad intelectual para los fenómenos religiosos. Y esta sensibilidad no se ha proyectado de una manera suficiente sobre nuestra historia y cultura, ni ha abordado los hechos por su diámetro más ancho, que conceptualmente es el de lo «religioso» antes que el de «cristiano», y el de «sagrado» antes que el de «heterodoxo» o que el de «ortodoxo». Y una visión discriminadora de los hechos religiosos exigirá siempre esa específica sensibilidad aludida, so pena de empequeñecer la real dimensión de la órbita religiosa por medio de una serie de reducciones. Reducciones que son explicables en los viejos historiadores de la «España Religiosa» y de la «España Sagrada», pero que lo serían menos en sus continuadores de hoy; hoy no sería posible seguir circunscribiendo la España religiosa a la España cristiana, la España cristiana a la España eclesiástica y la España eclesiástica a la España de los fastos episcopales... Esto lo vislumbró en su gloriosa madurez Menéndez Pelayo al propugnar la Ciencia de las Religiones como un saber fértil para la Hispanística. A tal posibilidad, acreditada en primer lugar por la propia tarea del maestro, se añaden, como hemos visto, la necesidad de incorporar a la Historia General de las Religiones los hechos del afluente hispánico $[\ldots]^{123}$.

Álvarez de Miranda, si bien en este trabajo es donde se reconoce de modo más público (pues lo dictó ante una sala abarrotada) y más programáticamente cerca (y a la vez lejos) de Menéndez Pelayo, citó a este autor en diversas otras ocasiones. Ya en uno de sus primeros trabajos, publicado en 1945, le sirve de referencia para reivindicar la recuperación del griego y la herencia griega clásica en la formación cultural española ${ }^{124}$. También acude a una cita suya como referente del interés de la cultura española por lo hispanoamericano (y viceversa $)^{125}$.

Pero el trabajo en el que hace una más sistemática utilización, pues lo cita en una decena de ocasiones y además se fecha en los mismos meses en que preparaba su

\footnotetext{
Álvarez de Miranda 1955, 32-34; 1959b, 311-312.

Álvarez de Miranda 1955, 36-37; 1959b, 314.

Álvarez de Miranda 1945, 27.

125 Álvarez de Miranda 1950a, 98 (1959a, 301); 1950b, 64 y 73 (1959a, 332 y 346). También se refiere a él en su tesis italiana, pero en un contexto sin relevancia analítica para nuestros propósitos, al hablar de las Cantigas de Santa María: Álvarez de Miranda 1952a, 214-215 nota 10; 2010, 83 nota 136
} 
primera lección como catedrático es en el que tituló «Cuestiones de mitología peninsular ibérica», ya antes repasado, pues hemos visto que también citó en él a Pettazzoni. Pero si bien su maestro italiano aparece de modo algo tangencial, Menéndez Pelayo es una cita recurrente. De hecho el trabajo empieza con un epígrafe que titula «La invitación de Menéndez Pelayo» donde expone el mismo argumento que en su primera lección y también incluye una larga cita del autor. Plantea que cuando el Menéndez Pelayo de la madurez dedicó un volumen completo a la «religiosidad precristiana» estaba marcando un camino que es el que ahora el está recuperando y que nadie hasta ese momento había emprendido de modo suficientemente adecuado. La cita donde detalla el argumento más claramente es la siguiente:

En estas palabras del maestro merece, ante todo, aprehenderse el contenido esencial de su mensaje, esto es, la paladina invitación de Menéndez Pelayo a abordar el estudio de algunos fenómenos religiosos españoles según un diámetro más ancho que el habitual de la Historia Eclesiástica, sometiéndolos al tratamiento peculiar de la Historia de las religiones; y también, más particularmente, al de la Mitología como ciencia que por medio del estudio de los específicos contenidos imaginativos del mito es capaz de palpar el reducto íntimo de las intuiciones religiosas propias del hombre arcaico. Esta expresa invitación no ha ejercido en la ciencia española posterior a él -por lo menos en la del menéndezpelayismo estricto y tradicionalun estímulo demasiado vivificante. Acaso por eso mismo no se haya reconocido bastante lo que de anticipadora adivinación acerca de las tareas de nuestro futuro historiográfico había en estas palabras de Menéndez Pelayo: adivinación cuyo mérito no queda disminuido, en nuestra opinión, por algunos disculpables criterios ideológicos e interpretativos -hijos más bien de las tendencias propias de su época-, que se transparentan ya en sus mismas palabras: así, por ejemplo, la indiscriminada recepción de las pretensiones comparativas de Max Müller en el campo de la Mitología; o también el preconcepto romántico de que los gérmenes secretos de la heterodoxia se alberguen en el estrato subterráneo, prehistórico y anónimo de las religiones primitivas más bien que en las corrientes históricas, disgregativas e individualísticas que nacen del heresiarca como de un tipo religioso turbado por urgencias generalmente coetáneas a él. ${ }^{126}$

Se trata, desde luego, y otra vez, de una reivindicación matizada, y presenta el interés de introducir otro personaje como es Max Müller, al que citó también en su primera lección para discutir su célebre aforismo de que «quien no conoce más que una religión, no conoce ninguna» ${ }^{127}$.

El resto de las referencias a Menéndez Pelayo en este trabajo que comentamos inciden en el carácter de heredero de su ambición que reivindica, planteando que hay que: «procurar llevar adelante, y en lo posible modernizar y actualizar, la vieja invitación de Menéndez Pelayo» ${ }^{128}$ y cerrando el artículo con: «es lo que ya sugirió Menéndez Pelayo, y lo que principalmente desean actualizar estas esquemáticas reflexiones sobre cuestiones de Mitología peninsular ibérica» ${ }^{129}$.

\footnotetext{
126 Álvarez de Miranda 1959b, 182-183.

127 Álvarez de Miranda 1955a, 8; 1959b, 291-292.

128 Álvarez de Miranda 1959b, 193 (referencias previas generales en 185-186)

129 Álvarez de Miranda 1959b, 210.
} 
En suma, el entonces reciente catedrático plantea lo cerca que estaba el trabajo de madurez de Menéndez Pelayo de lo que se podía hacer desde la Historia de las Religiones. En su afán de expandir su análisis de la religión en España, Menéndez Pelayo había terminado estirando el argumento de tal modo que de hecho se había apartado del corsé intelectual que encerraba su obra como consecuencia de ceñirla al concepto heterodoxia-ortodoxia. Había desembocado en la necesidad de reflejar un contexto de pluralidad de religiones, las que existían en la Península Ibérica con anterioridad al cristianismo católico. Y al dedicarle un voluminoso tomo en tanto que precursoras de las futuras heterodoxias (débil argumento como no deja Álvarez de Miranda de evidenciar), estas religiones no podían menos que desmontar la ecuación españolidad igual catolicidad. Por tanto Álvarez de Miranda, si bien no dejaba, al plantear como uno de sus referentes intelectuales a Menéndez Pelayo, de plegarse formalmente a lo intelectualmente correcto en la universidad en cuyo claustro acababa de entrar, y lo había hecho tanto en su lección primera como en su primer artículo en la revista general de la institución, en última instancia, al detectar las limitaciones del «maestro», terminaba desvelando el tenor del nuevo proyecto que la Historia de las Religiones podía llegar a proponer, por mediación suya, para irradiar en la universidad española. Se trataba de una construcción intelectual caracterizada por la especial sensibilidad respecto de la diversidad de religiones del pasado, que podía no respetar la incomparabilidad y preeminencia que muchos deseaban para la religión nacional, y que no podía menos que asustar a algunos de sus oyentes y lectores. No es de extrañar que a su muerte, en un contexto universitario de involución tras la caída en desgracia del ministro Ruiz-Giménez, que conllevó la destitución también de Laín, la cátedra terminase desapareciendo.

Otro de los referentes intelectuales de Álvarez de Miranda, y en este caso, parece que sin reticencias, era José Ortega y Gasset. Lo expone, además, recordando el testimonio de Carlos París, Onésimo Díaz ${ }^{130}$, y puebla un buen número de citas que el autor no tiene empacho de incluir a lo largo de sus trabajos más generales y desde sus primeros artículos de entidad, a pesar de que el tema de las religiones sea uno de los menos fáciles de reivindicar en la obra orteguiana (por su escasa presencia). En su segundo artículo de entidad, publicado en 1945, incluyó a Ortega junto a d'Ors en una primera cita sin referente bibliográfico, pero páginas después, al disertar sobre la deshumanización del arte le dedica una nota admirativa ${ }^{131}$. En muchos de sus trabajos para Cuadernos Hispanoamericanos de 1948 aparece como referente, denominándole «nuestro filósofo» ${ }^{132}$ o protestando porque no se le haya incluido en la lista de los «pensadores modernos dotados de logos profético» ${ }^{133}$. En 1950 aparece en una serie de trabajos generales o enfocados en el tema americano y que no tienen que ver con la historia de las religiones. En su libro Perfil cultural de Hispanoamérica, incluye su obra como referente del pensamiento español en

130 Díaz 2007, 212 nota 30: «Según Carlos París, Tena y Álvarez de Miranda eran profundamente orteguianos (entrevista del autor a Carlos París, Madrid, 5.XII.2003)». El aprecio a Ortega lo heredaron también sus mejores discípulos, incluso a costa de posibles disgustos, pues no tuvo empacho en recibir en Roma, en el Instituto que dirigía, y a instancias de Dionisio Ridruejo, a María Zambrano, como recordaba José Miguel Velloso (1976, 115) y cita su hijo Pedro (en Díez de Velasco/Álvarez de Miranda 2010, 561).

131 Álvarez de Miranda 1959a, 32 nota 1 y 51 y nota 1.

132 Álvarez de Miranda 1948a, 363.

133 Álvarez de Miranda 1948j, 211. También en Álvarez de Miranda 1948i, 93. 
América en cuatro ocasiones ${ }^{134}$, también lo hace en relación con su caracterización de Unamuno ${ }^{135}$ o en una docena de ocasiones en unas reflexiones sobre el modernismo español donde defiende que se trataría de su verdadero representante ${ }^{136}$. Pero será ya en su plena época de madurez formativa en Italia, y justamente en una nota sobre el pensamiento mitológico en Ortega, donde interconecte de modo muy interesante a una serie de intelectuales que aparecen como sus referentes junto al propio Ortega. La redactó en noviembre de $1953^{137}$ en Roma y la hizo llegar al semanario que tomaba el nombre de Revista y capitaneaba su amigo Dionisio Ridruejo (con el que había coincidido en Roma en su época de corresponsal y al que se había llegado luego a tantear para sucederle como director del Instituto Español en Roma al ganar la cátedra) ${ }^{138}$. En esta época Ridruejo ya abanderaba un larvado (o manifiesto) descontento frente a ciertas (o muchas) derivas del franquismo. En este escrito Álvarez de Miranda está actuando como intelectual español afecto a Ortega y a su influencia pero también como representante de una política cultural española en el extranjero que ya ha reivindicado en diversos foros con anterioridad ${ }^{139}$. Quiere en particular mostrar la riqueza del pensamiento orteguiano en relación con la mitología y evidenciar el impacto internacional que ha tenido. Ya adelantamos que citó a Pettazzoni en este trabajo, pero recuperar el párrafo completo resulta clarificador de su recurso a la atalaya romana desde la que escribe (y donde llega a escuchar personalmente a quienes cita) para apuntalar el prestigio de Ortega, evidentemente frente a quienes le menospreciaban en su propia patria (no pocos de ellos, además, en esta etapa de nacionalcatolicismo oficial, por su tibieza en cuestiones de religión):

[...] había de ser un especialista -el estudioso actual que más libros y fatigas ha dedicado a los estudios mitológicos, Kerényi-, quien acogiese íntegramente las palabras de Ortega, enfocándolas hacia el mito como la mejor definición y aclaración de su esencia y de su función dentro de la humanidad arcaica. Kerényi ha lanzado a los cuatro vientos las imágenes orteguianas. Las ha acogido literalmente, y desde entonces sus libros y conferencias suelen glosar y orquestar con vehemencia las ideas de nuestro pensador. (El curioso lector lo puede ver en libros suyos como «Introducción al estudio científico de la Mitología», Berna, 1946, o «La religión antigua en sus líneas fundamentales», Amsterdam, 2. ed., 1942 $2^{140}$; y en dos conferencias suyas oídas en fechas diversas (quien esto escribe asistió ${ }^{141}$ a la explícita alusión gratulatoria de Kerényi al mérito de Ortega y a la insustituible lucidez de sus imágenes e ideas). La cosa es ya tan notoria que hablando del mitólogo los

134 Álvarez de Miranda 1959a, 246; 291-292; 301, aunque sin referencia bibliográfica detallada.

135 Álvarez de Miranda 1950b, 58; 1959a, 321.

136 Álvarez de Miranda 1951 (en 1959a, 355, 360, 363-365 en múltiples ocasiones).

137 Álvarez de Miranda 1953e.

138 Lo expone Pedro Álvarez de Miranda con detalle y documentación (en Díez de Velasco/Álvarez de Miranda 2010, 562); Velloso 1976 rememora esta etapa de la vida de Ridruejo.

139 Álvarez de Miranda 1948i; 1950a (en cierta medida); 1950c y 1952c (ambos de modo muy claro), lo trata con detalle, citando párrafos (ya que se trata de un documento inédito) su hijo Pedro (en Díez de Velasco/Álvarez de Miranda 2010, 550ss.).

140 En su biblioteca privada tenía la traducción italiana publicada en 1951 en la editorial Astrolabio de Roma, la primera edición italiana había aparecido una década antes en la colección Storia delle religioni de la editorial Zanichelli que dirigía Pettazzoni.

141 Dio tres conferencias en diciembre de 1950 en Roma (las revisa Gandini 2006a, 226-227), alguna de las cuales escuchó Álvarez de Miranda; dio otra en diciembre de 1951 en que estuvo presente y cita en su tesis italiana (Álvarez de Miranda 1952a, 233 nota 90; 2015, 146 nota 267). 
críticos señalan ahora en él la feliz influencia recibida del español (véase, por ejemplo, el Prefacio del profesor Brelich a la edición italiana de «Hijos del sol», Turín, 1949 ${ }^{142}$ ). Y, sobre todo, ocurre que a estas alturas, expresa o tácitamente, los muy diversos estudiosos acampados en asedio frente al hermético fenómeno de las mitologías - psicólogos como Jung, historiadores de las religiones como Pettazzoni-, ejercitan una poliorcética de signo orteguiano. ${ }^{143}$

Aquí junto a Pettazzoni aparecen otros dos referentes intelectuales de Álvarez de Miranda: Karl Kerenyi y Angelo Brelich. El segundo, que sucederá a Pettazzoni en su cátedra romana y es reconocido como su discípulo predilecto, empezó justamente teniendo a Kerenyi como maestro, aunque terminó distanciándose de él (lo mismo que el propio Pettazzoni, resultando muy significativo que Kerenyi estuviese en Roma en las fechas en que se celebró el VIII congreso de Historia de las Religiones en 1955 y no asistiese al mismo ${ }^{144}$ ). Álvarez de Miranda trató personalmente a Brelich en las reuniones del Istituto di Studi Storico-religiosi de la Universidad de Roma y en las de la Società Italiana di Storia delle Religioni ${ }^{145}$ y eran casi coetáneos (el español era año y medio más joven). Si bien cita a Brelich en relación con Kerenyi también en su tesis italiana ${ }^{146}$, insiste en reconocer la valía de su trabajo propio de un modo que no solía ser usual en el autor (con los epítetos de agudo y sugerente) $)^{147}$. Por su parte Kerenyi es, desde luego, un autor predilecto de Álvarez de Miranda cuando aborda el análisis mitológico. Ya hemos visto que se refiere a él tres veces en relación con Ortega, que en su tesis italiana usa sus trabajos dos veces y una de ellas refiriéndose a una conferencia a la que asistió y que impartió en diciembre de 1951 en el Instituto Histórico Holandés en Roma ${ }^{148}$, por su parte en «Poesía y religión», al plantear el concepto de mitologema, su referencia única es el trabajo de Jung y Kerenyi ${ }^{149}$. Pero donde ahonda en mayor medida en las referencias es en su artículo quizá más internacional (no solo por el detallado aparato de citas y fuentes que maneja sino también por la sofisticación del método comparativo que emplea), el que trató de Job y Prometeo, donde la monografía de Kerenyi sobre Prometeo es elemento bibliográfico clave con el que dialoga ${ }^{150}$. $\mathrm{Al}$ aceptar la propuesta de Kerenyi de figurar a Prometeo como mitologema de lo humano y sus límites, está quizá desbordando las fronteras del más clásico análisis histórico-religioso. Si combinamos su gusto por Eliade con el que tiene por Kerenyi, se evidencia una trayectoria que con el tiempo hubiera deparado quizá

142 Libro que tenía en su biblioteca privada.

143 Álvarez de Miranda 1953e, 7; 1959a, 381.

144 Gandini 2007b, 167.

145 En la correspondencia entre Pettazzoni y Álvarez de Miranda que se conserva en San Giovanni in Persiceto hay una cartulina en la que Álvarez de Miranda se disculpa de no haber podido escuchar a Brelich en la reunión del 21 de marzo de 1953 (material revisado en Gandini 2006b, 117-118), el tenor del texto evidencia que se trataba de una asistencia habitual por su parte, y la antes citada última carta de Pettazzoni de 1956 recordando su presencia en este tipo de reuniones lo confirma.

146 También en la tesis italiana: Álvarez de Miranda 1952a, 234 nota 104; 2015, 152 nota 280, indica que el traductor era también Brelich por error, ya que solamente era el autor del prefacio.

147 Álvarez de Miranda 1956, 62; 1959 b, 428 nota 1 dice: «Un agudo planteamiento para una revisión actual de las religiones griega y romana puede verse en el sugerente estudio de A. Brelich, Religioni antiche e pensiero contemporáneo (Maia, HE, fase. III, págs. 165-175, Roma, 1948)».

148 Álvarez de Miranda 1952a, 233 nota 90; 2015, 146 nota 267.

149 Álvarez de Miranda 1959b, 40 nota 2; 2010, 128-129 nota 4.

150 Álvarez de Miranda 1959b, 246, 247 y nota 1,266 nota 3, 284 nota 1. 
un Álvarez de Miranda cercano a propuestas como las del Círculo Eranos como ha propugnado Andrés Ortiz-Osés ${ }^{151}$.

Así como hemos visto que Ortega era un pensador para el que lo religioso no era asunto particularmente de interés, en el siguiente referente intelectual de Álvarez de Miranda, Xavier Zubiri, la religión era una referencia constante y seminal y su libro Naturaleza, Historia, Dios de 1944, una lectura de cabecera de nuestro autor. Álvarez de Miranda le admiraba y le dedicó la primera cita en su primer artículo de envergadura. «Los griegos no son nuestros clásicos; es que, en cierto modo, los griegos somos nosotros $\rangle^{152}$ es el argumento zubiriano con el que comienza a discurrir sobre Tucídides ${ }^{153}$. También usó su aproximación a Sócrates de modo elogioso en la introducción al Fedón ${ }^{154}$, que publicó en 1948. Pero será en lo relativo no al mundo clásico, sino al estudio de las religiones donde el influjo zubiriano será más palpable. En «Poesía y religión», Zubiri y su concepto de religación es utilizado para construir la base teórica del trabajo de comparación que requiere su análisis de García Lorca:

[...] al hablar aquí de religiosidad y de religión no se alude para nada a todo cuanto es peculiar y privativo del Cristianismo; se alude, en cambio, a esa dimensión expresada por Zubiri bajo la fórmula de «la constitutiva religación de la existencia humana»; religación en la cual lo primero que se hace patente no es Dios, sino la deidad: deidad sobre la cual se articula la religión natural, anterior a la revelación. Dentro de esa religión natural, que históricamente se ha manifestado en diversos sistemas de «sacralidades» y «numinosidades» (esto es, de religiones), hay una religión, o más exactamente, hay un tipo de religiosidad, basada en sacralidades naturalísticas fundadas muy especialmente sobre la sacralidad de la vida orgánica, que es percibida por la mentalidad arcaica como multiforme misterio y numinosidad. Pues bien, esta religión natural, y además naturalística, y, sobre todo, vitalística, es la que entra en juego aquí. ${ }^{155}$

En «Job y Prometeo» dedica a Zubiri el colofón de su artículo en el que expone uno de sus temas más queridos, el de la irreligiosidad que se entrelaza con el de la «constitutiva religación de la existencia humana» zubiriana, en una cita que desarrolla del siguiente modo en la nota bibliográfica:

Las consideraciones del filósofo español acerca del ateísmo como problema filosófico y acerca de su manifestación a través de la Historia son susceptibles de precisa aplicación al caso de la actitud prometeica: ella constituye, acaso, la más antigua ilustración histórica de la irreligiosidad como figura religiosa. ${ }^{156}$

En una corta nota que se publicó en diciembre de 1953, se nos aclara el origen del interés de Álvarez de Miranda por la irreligiosidad, tema que trabajó en su tesis

151 Ortiz-Osés 2000, 119; 2008, IX.

152 Zubiri 1944, 410.

153 Álvarez de Miranda 1945a, 111; 1959a, 5 y nota 1.

154 Álvarez de Miranda 1959a, 196 nota 1, cita a Zubiri 1944, 187ss.

155 Álvarez de Miranda 1959b, 47 y nota 1; 2010, 128 nota 2, cita en este trabajo específicamente la segunda edición del libro de Zubiri.

156 Álvarez de Miranda 1954b, 237; 1959b, 284-285 nota 2, cita por la segunda edición (Zubiri 1951, 355ss.). 
española y sus artículos aledaños, incluido Job y Prometeo, y que es uno de los elementos que resultan más actuales en el pensamiento histórico-religioso del autor. Es un interés y un enfoque que bebe en Zubiri: "Todo ello muestra la honda verdad de aquello que Zubiri escribió, hace ya casi veinte años, de que el problema religioso de hoy consiste [...] en el problema religión-irreligión» ${ }^{157}$.

Hay que añadir que Zubiri y Álvarez de Miranda, además, eran amigos y presentaban ciertas afinidades como orteguianos, vascos y antiguos seminaristas que eran. Álvarez de Miranda nunca se ordenó mientras que Zubiri se secularizó y contrajo matrimonio, lo que le llevó a ser muy mal visto por buena parte del clero español, de ahí que Álvarez de Miranda al otorgar a Zubiri la relevancia de citarlo estaba claramente tomando partido por la inteligencia frente a la conveniencia. Y fue una amistad que se mantuvo hasta el final de la vida de Álvarez de Miranda y sabemos por una carta del 27 de agosto de 1956 que envió a Aranguren ${ }^{158}$, aunque la escribió y firmó Consuelo de la Gándara, ya que su enfermedad se lo impedía, que Zubiri había visitado al enfermo en dos ocasiones ese verano y le había leído partes del libro que tenía en preparación.

Zubiri nos ha llevado a introducir a otro referente intelectual de Álvarez de Miranda, pero en este caso, y parecido a lo que ocurría con Brelich, se trataba más de un par suyo que de un maestro. Se trata de José Luis López Aranguren, que aunque era un poco mayor, mantenían entre ambos una relación de compañerismo. No encontramos citas de Aranguren en la obra de Álvarez de Miranda hasta uno de sus últimos escritos, que envía a Cuadernos Hispanoamericanos en 1955, cuando ya está perdiendo de modo definitivo la capacidad de escribir ni aún con ayuda. Se trata de la reseña de la monografía que refleja la tesis doctoral de su amigo, defendida en 1951, sobre el protestantismo ${ }^{159}$, un tema sobre el que había publicado previamente otro libro ${ }^{160}$ un año después de la tesis y que le había granjeado muy duras críticas, especialmente por parte de intelectuales jesuitas. La reseña de Álvarez de Miranda es cautamente académica pero muy elogiosa y termina con un claro apoyo a su autor:

[...] el plus pretendido y logrado por Aranguren consiste en perseguir el ethos íntimo del protestantismo, en tanto que actitud religiosa de la que dimana precisamente una determinada organización del mundo moral. Si se hubiese limitado a lo primero, este libro mantendría intactos sus méritos como investigación histórica. Pero lo segundo no es solamente una generosa añadidura, sino más bien una exigencia previa que el autor se ha impuesto al acometer el tema en su más profunda dimensión y al desarrollarlo con esa específica sensibilidad intelectual para los fenómenos religiosos que constituye uno de los rasgos más característicos de la personalidad de Aranguren, cuyo libro, en fin, satisface cumplidamente y, al mismo tiempo, rebasa los intereses de una investigación meramente positiva sobre la moral del protestantismo ${ }^{161}$.

157 Álvarez de Miranda 1953h, 7; 1959a: 391.

158 Conservada en el Archivo Aranguren en el CSIC en Madrid (signatura AFI-AA-CO-A4-146-3).

159 Aranguren 1954.

160 Aranguren 1952.

161 Álvarez de Miranda 1955e, 261. 
Mucho más diáfana resulta su opinión expresada en su correspondencia. En una carta del 17 de marzo, mecanografiada y con membrete de catedrático de la Universidad de Madrid, dice lo siguiente:

Querido José Luis: Ya que no puedo congregarme esta noche contigo y con los amigos, sumándome a tu homenaje, quiero hacerte llegar de alguna manera mi identificación con el gesto de afecto hacia tu persona y de admiración hacia tu obra que ha movilizado a los participantes en esa reunión. Leyendo tu espléndida obra pienso que actitudes como la tuya representan una especie de nupcia, tan dichosa como infrecuente entre nosotros, de puro catolicismo y clara inteligencia. Libros como el tuyo indemnizan a este país de tres lustros de religiosidad más fértil en producir jenízaros que verdaderos pensadores. Un abrazo, con toda la admiración y la amistad de tu amigo ${ }^{162}$.

Dos meses antes había escrito otra nota, manuscrita (pero de la mano de su esposa Consuelo de la Gándara, salvo en la temblorosa firma), en la que le explicaba detalles de la reseña:

Querido José Luis: he escrito para "Cuadernos" la glosa adjunta. Nadie mejor que tu apreciará lo superficial que es. Sin embargo he querido hacértela, olvidando por una vez lo ancha que me viene la crítica filosófica y teológica, deseoso de mostrarte de algún modo mi gratitud como lector y mi admiración intelectual por tu obra. Un abrazo de tu amigo. Ánge1 ${ }^{163}$.

De todos modos, Álvarez de Miranda se había atrevido, previamente a su estancia romana, a traducir en 1948 un libro de Jacques Maritain ${ }^{164}$ que podía traerle problemas tanto por la posición de su autor respecto del franquismo como por el tema tratado, ya que disertaba sobre Lutero, Descartes y Rousseau, autores que solo aparecen reflejados en el título en la edición más reciente. Con ello estaba posicionándose de un modo que podemos enjuiciar, por ejemplo, como convergente con su mentor Ruiz-Giménez ${ }^{165}$, en la apuesta por otorgar voz a un católico comprometido pero a la vez un intelectual muy influyente que no desdeñaba, como Aranguren, lanzar la mirada hacia el promotor de la Reforma. Recordemos que Aranguren y Laín convergen con Álvarez de Miranda formando el núcleo intelectual de un grupo capitaneado por el ministro Ruíz-Giménez. Tenían una idea de la cultura española y del papel que los intelectuales debían cumplir en ella que se truncó a la par que agonizaba Alvarez de Miranda y Franco destituía a su ministro de educación. Los tres supervivientes lamentaron su pérdida con sentidos recuerdos, aunque el primero en hacerlo, en 1957 fue Aranguren en la revista que dirigía Camilo José Cela ${ }^{166}$, mientras que Laín y Ruíz-Giménez adornaron a partir de 1959 las obras póstumas de Álvarez de Miranda con sus prólogos ${ }^{167}$. Parecían lamentarse no solo del amigo muerto, sino también de

\footnotetext{
162 En el Archivo Aranguren en el CSIC en Madrid (signatura: AFI-AA-CO-A4-146-2).

163 En el Archivo Aranguren en el CSIC en Madrid (signatura: AFI-AA-CO-A4-146-1)

164 Maritain 1948.

165 Que dirigirá, por ejemplo, la tesis sobre Maritain de Gregorio Peces Barba, leída en 1970.

166 Aranguren 1957, luego recuperado como epílogo de Álvarez de Miranda 1959b.

167 Ruíz-Giménez en Álvarez de Miranda 1959a, VII-XVIII; Laín en sendos prólogos en Álvarez de Miranda 1959b, IX-XVIII y Álvarez de Miranda 1961, IX-X.
} 
la fatalidad que simbolizaba la oportunidad perdida para la universidad y para la cultura española al caer el ministerio en manos de dirigentes con perspectivas diferentes y que tras la fachada de la tecnocracia amparaban modelos ideológicos muy alejados de los suyos y que propiciaron una evidente involución cultural.

Queda por repasar el último de los prologuistas póstumos de Álvarez de Miranda, amigo suyo y estricto coetáneo (solo cuatro meses mayor que él), Julio Caro Baroja, otro símbolo de la oportunidad perdida para la universidad española, asunto que no dejó de evidenciar el propio Álvarez de Miranda, sin nombrarle expresamente, en una nota programática que tituló «Urgencia de la etnología en la Universidad», que no puede ser más elogiosa:

[...] no faltan hoy en España algunos investigadores meritísimos con óptima labor etnológica cumplida. Incluso entre ellos alguno que está siendo creo que más estimado fuera de España: curiosa paradoja la de que haya entre nosotros efectivos maestros sin posibilidad de ejercer el magisterio que realmente están ya ejerciendo a fuerza de inteligencia y de heroica vocación ${ }^{168}$.

Quizá, entre los investigadores españoles, Caro era el único que hubiera podido compararse a Álvarez de Miranda por el conocimiento que tenía de la Historia de las Religiones (aunque probablemente hubiese denominado de otra manera a la disciplina). En su trayectoria posterior de publicaciones hay algunos títulos, incluso de notable impacto internacional, que lo avalarían como tal. Álvarez de Miranda le dedicó, ya en 1948, en Cuadernos Hispanoamericanos, una reseña de cuatro densas páginas a su Los pueblos de España, donde lo denomina «joven maestro de la Etnología española» y valora su encuadre metodológico: «su mirada es objetiva e incluso fríamente valoradora», y dibuja sus análisis sin compasión, con una «mano insobornablemente científica - a veces, incluso, un poco desalmada- $\gg{ }^{169}$. Caro, que redactó el prólogo a la traducción al español de la tesis italiana de su amigo realizada por su esposa, no deja de recordar sus posiciones diferentes frente al objeto de estudio:

De vez en cuando nos veíamos [...] y discutíamos sobre asuntos que a mí me habían apasionado entre los veinte y los treinta años, y que a él le apasionaban: las religiones prehistóricas, los cultos mediterráneos, la filosofía de los mitos, el estudio comparado de las religiones... Todos estos grandes temas, propios para ilusionar a un joven humanista moderno, se movían y removían en la conciencia de Álvarez de Miranda, hombre piadoso, para el que la religión era acaso la razón mayor de la existencia. Una conciencia más fría, como era y es la mía, tenía que perder el entusiasmo por los misterios místicos con mayor facilidad. ${ }^{170}$

Álvarez de Miranda citó los trabajos de Caro en diversos contextos. Hace en su tesis italiana y en los artículos derivados de ella, por una parte, un uso sistemático de Los pueblos de España, tanto para citar puntos en los que Caro trata del toro, como para reflejar la crítica que vertía contra los tratadistas sobre el asunto que erraban al

168 Álvarez de Miranda 1953d, 221.

169 Álvarez de Miranda 1948e, 588, 589, 591.

170 Álvarez de Miranda 1962, 8; 1998, 11-12; 2015, 6-7. 
reflejar las épocas más antiguas ${ }^{171}$, y por otra parte, utiliza varias veces su Algunos mitos españoles ${ }^{172}$. Pero quizá las citas más interesantes de Caro sean las que incluye en el que parece que fue el último trabajo que escribió, que se dedicaba al padre Wilhelm Schmidt y España. En su programática primera lección había obviado a Schmidt a la par que a Pettazzoni, ya lo vimos. En este trabajo, en cierto modo paga la deuda con Schmidt, y lo hace en Arbor, la revista del Consejo Superior de Investigaciones Científicas, donde sabemos por su carta a Pettazzoni que está a punto de encargarse, como director, de la sección de Historia de las Religiones. Al repasar la recepción de Schmidt en España cita a dos autores:

Y casi podría decirse que en Barandiarán se cifra toda la receptividad de la ciencia española ante la obra del P. Schmidt, si no fuera por el eco que de ella se ha hecho también Julio Caro Baroja, que en su Análisis de la cultura añade a la exposición de la doctrina del P. Schmidt una lúcida estimación de la misma desde la perspectiva actual de la ciencia etnológica. ${ }^{173}$

Caro le sirve para introducir la perspectiva crítica frente a Schmidt, que comparte en tanto que discípulo de Pettazzoni, pero que hace de un modo muy suave, como no podía plantearse de otro modo en una institución en general, y un foro en particular, en el que las sensibilidades ideológicas de sus directivos eran evidentes (recordemos que era Rafael Calvo Serer, notorio miembro del Opus Dei, quien en esa fecha gobernaba la revista). Además eran posiciones enfrentadas al grupo de católicos de perspectiva más abierta en el que se insertaba Álvarez de Miranda, y capitaneaba Ruíz-Giménez, cuya prevista y nunca desarrollada intrusión en el CSIC parece una maniobra del estilo, para usar un símil clásico, de «caballo de Troya».

Caro vuelve a aparecer y esta vez usando al padre Schmidt como excusa, en una nueva reivindicación de la etnología y su posición en España:

[...] una dichosa superación en nuestros días de las inveteradas limitaciones y olvidos de la ciencia española en el ámbito etnológico se puede cifrar en empresas actuales de tanto alcance como la de Julio Caro Baroja. Superación que consiste no sólo en el modo con que este estudioso ha abordado la etnología peninsular depurando su tono científico e introduciendo en ella criterios, soluciones y perspectivas nuevas, sino en la extensión de la tarea de Caro Baroja al área etnológica extrapeninsular. Una brillante muestra de esto último es su reciente libro Estudios saharianos, fruto de una campaña entre los nómadas del Sáhara occidental que constituye la aportación científica española más notable en los tiempos modernos a un tema de la Etnología africana ${ }^{174}$.

La figura de Julio Caro Baroja nos ha servido de preámbulo para pasar ahora a terminar de cerrar la revisión de Wilhelm Schmidt como referente intelectual de

171 Álvarez de Miranda 1952a, 204 nota 30; 2015, 27 nota 42; Álvarez de Miranda 1952a, 208 nota 42; 2015,52 nota 84; en Álvarez de Miranda 1952a, 78, 214 nota 2; 2015, 79 nota 128 el toro se combina con costumbres de «fisonomía matriarcal», en expresión de Caro (asunto que retoma sin referencia bibliográfica en Álvarez de Miranda 1954d, 204); también Álvarez de Miranda 1953a, 321, 324; 1959b, 35 nota 4 y 37 nota 3.

172 Álvarez de Miranda 1952a, 47, 209 nota 1; 2015, 55 nota 85 cita la segunda edición, de 1944 y retoma la referencia aunque sin cita de bibliografía detallada en Álvarez de Miranda 1954d, 184.

173 Álvarez de Miranda 1955h, 282; 1959b, 367-368.

174 Álvarez de Miranda 1955h, 286; 1959b, 371-372. 
Álvarez de Miranda. Cuenta Ramón Valdés del Toro, que en las clases de su maestro a las que asistió: "habló del padre Schmidt [...] y dijo cosas que me parecieron agudas y acertadas ${ }^{175}$. Le había citado, como vimos, en su trabajo de cátedras sobre las religiones mistéricas de un modo forzado que quizá tomaba el lugar de la cita que hubiera debido dedicar a Pettazzoni. También vimos que obvió a ambos en su primera lección y que en cierto modo en su último artículo en Arbor intenta pagar la deuda, resaltando lo poco que se había traducido al español del autor ${ }^{176}$. También en el número anterior de la misma revista había incluido una reseña al último tomo publicado hasta ese momento, el XI, del monumental Der Ursprung der Göttesidee donde, además, recordaba la muerte del autor y adelantaba la inminencia del último volumen, ya póstumo, de la serie. No cita a Pettazzoni, evidentemente, pues sería apostar de modo demasiado claro por un camino a seguir, en especial si su entrada en el CSIC iba a incluir una visita con honores de su maestro italiano, como vimos que planteaba en su correspondencia. Pero no deja de ofrecer el contrapunto, de un modo muy matizado, pero bien evidente, de la base teórica del libro que está reseñando:

Incluso quienes no comparten la doctrina del Urmonotheismus, y los que en el terreno de la Etnología sean adversarios u objetores del método histórico-cultural, no podrán regatear a este libro el evidente mérito de ser la aportación más definitiva hasta ahora al conocimiento de las arcaicas religiones de los pastores siberianos $^{177}$.

El mero uso del término doctrina para calificar el Urmonotheismus parece una sutil descalificación del aroma teológico de la propuesta. En el enfrentamiento Schmidt/Pettazzoni la posición de Álvarez de Miranda no ha podido expresarse de modo explícito en estas obras, pero sí implícito para quien quiera leer entre líneas, por tanto se puede defender que Schmidt no le resulta un referente comparable a su maestro italiano, por mucho que las circunstancias de la España del momento pudieran exigirlo.

Nos queda por repasar otro, en este caso sí, verdadero referente intelectual de Álvarez de Miranda: Gerardus van der Leeuw. Es tras Mircea Eliade y Pettazzoni el autor que más cita en asuntos de calado. Ya vimos, en la reseña que hace al Manual de Eliade, como decía que van der Leeuw era una «óptima compañía». No cita sus trabajos en su tesis italiana ni en los artículos derivados de ella quizá porque al centrarse en la religión y mitología del toro, resultaba un autor algo alejado de sus intereses y también quizá porque se le podría aplicar al respecto el mismo razonamiento antes expresado en el caso de Eliade. Pero, por el contrario, en el artículo derivado de su tesis española, van der Leeuw le ofrece un argumento clave para apuntalar su empeño de índole teórica de estudiar la irreligión desde los presupuestos de la disciplina que cultiva. Se está, por tanto, apoyando en el pensador holandés para uno de sus temas de investigación más queridos e interesantes y lo expone de la siguiente manera: «La ciencia de las religiones empieza a prestar especial atención a este tema de la irreligiosidad precisamente en función de ser una importante

Valdés 2006, 5 .

Solo Schmidt 1932.

Álvarez de Miranda 1955g, 172. 
"figura" religiosa. Cf. G. van der Leeuw, Phänomenologie der Religion. Tubingen, $1933 »^{178}$. Álvarez de Miranda está utilizando la edición alemana que vierte al español, ya que la traducción del libro, que aparecerá en México, en el Fondo de Cultura Económica, se demorará hasta 1964, casi 15 años después de la muerte de su autor. Por su parte en «Poesía y religión» hace un uso tan sistemático de la obra, que incluso empieza el trabajo con una cita de encabezado suya: «Ya ha pasado la hora en que se podía resolver la poesía no viendo en ella sino comparaciones emitidas por juego, y la religión viendo en ella tan sólo otra noción igualmente infantil ${ }^{179}$. Le resulta tan programática la cita que incluso llega a repetirla en el cuerpo del texto otra vez ${ }^{180}$. También recurre a van der Leeuw como argumento de autoridad a la hora de plantear la licitud del uso de las intuiciones poéticas como material de estudio de índole religiosa y, además, es la primera cita bibliográfica de su trabajo ${ }^{181}$. Y en la misma línea recurre a él para calibrar la fuerza misteriosa que anima lo natural y que se vehicula claramente en la poesía (y de forma evidente en la poesía lorquiana) con la cita: «Los poetas son ya los únicos buenos animistas en el seno de un mundo mecanizado» ${ }^{182}$. Van der Leeuw también le sirve de fuente de autoridad a la hora de analizar temas quizá complicados para la sensibilidad española del momento como eran los relativos a la sexualidad, pero fundamentales para entender a García Lorca. Así cuando evidencia la valoración de la fecundidad frente a la castidad en las sociedades antiguas usa a van der Leeuw de referente ${ }^{183}$. Cuando expresa la crudeza soteriológica lo hace por medio de la siguiente cita del autor: «Durante mucho tiempo la salvación no revistió ninguna forma: el primer salvador no es otro que el phallus que aporta la fecundidad $\rangle^{184}$. Cuando tiene que evidenciar el entrelazamiento de muerte y sexualidad opta por otra cita: «mística de la muerte, mística nupcial y erotismo se dejan difícilmente separar» ${ }^{185}$. También para ilustrar el tiempo cíclico entre los primitivos acude a van der Leeuw ${ }^{186}$, curiosamente en vez de a Eliade, a pesar de lo famoso que era en España el libro de éste último sobre el tiempo como resultado de las glosas que le había dedicado Eugenio d'Ors. Otras citas son más circunstanciales y asocia al autor con otros grandes referentes como Frazer ${ }^{187}$.

Ya hemos planteado que «Poesía y religión» es quizá la obra de Álvarez de Miranda en la que desarrolla del modo más ambicioso e interesante su apuesta por el método comparado adentrándose más allá de los territorios habituales de la historia de las religiones más clásica. Presenta una arquitectura de referencias muy significativa para el tema que estamos tratando: comienza con una cita de van der Leeuw y se cierra con otra de Eliade y en total cita once veces al primero y diez veces al segundo. Son, por tanto, sus referentes principales, por delante incluso de Pettazzoni al que solo se refiere en tres ocasiones.

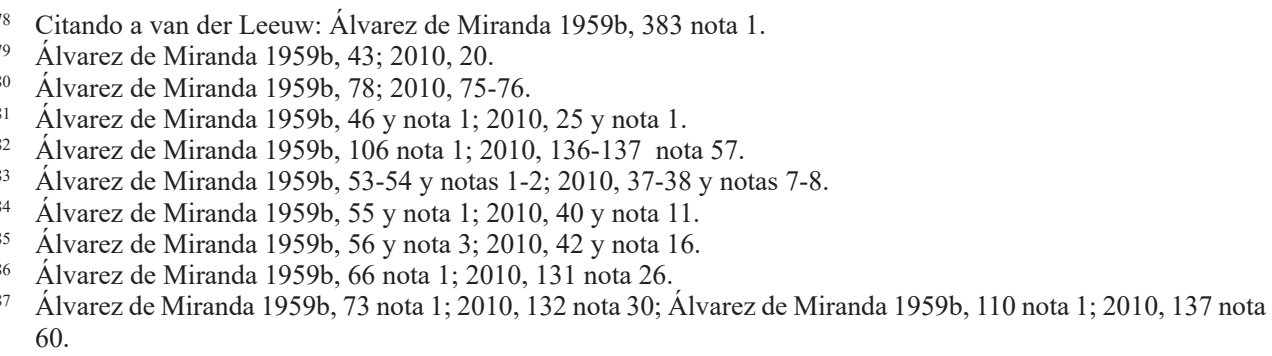


Este asunto lo vemos también claramente en su trabajo de cátedras, cuando repasa el estado de la cuestión en el campo de las religiones mistéricas hermana de modo muy interesante a los dos primeros:

No estará de más aludir también en esta reseña a algunas obras recientes incluibles, por diversas razones, entre los tratados generales de Historia de las Religiones [...] las más notables son las que constituyen una dirección científica nueva resumible como un predominio, en la Historia de las Religiones, del interés fenomenológico sobre el propiamente histórico. Así la gran obra de van der Leeuw, que no siendo ni pretendiendo ser una Historia de la Religiones, sino un estudio del fenómeno religioso en general, «en su esencia y manifestaciones», está ejerciendo un influjo en historiadores e historias de las religión propiamente tales; y sobre todo en la obra de Eliade. ${ }^{188}$

No podemos saber, en suma, la deriva que hubiera tomado Álvarez de Miranda en el caso de haber podido seguir con su brillante carrera de historiador de las religiones, pero frente a Pettazzoni o van der Leeuw, que representaban el pasado, y ahondando en el argumento adelantado en el apartado dedicado a Eliade, es bastante predecible que éste hubiese seguido siendo su referente intelectual principal, en la estela de tantos otros cultivadores de la disciplina a escala mundial, en particular tras la consagración estadounidense del rumano y, como vimos que ha expuesto Natale Spineto $^{189}$, siguiendo también los pasos de su maestro Pettazzoni en sus años finales.

\section{Bibliografía}

A. Álvarez de Miranda, «Reseña a L. Kösters, La iglesia de nuestra fe», Cisneros 5 (1943a) 179-180.

— «El retorno del nieto de Renan», Cisneros 7 (1943b) 99-101.

- «Una primera guerra europea narrada por Tucídides», Revista de estudios políticos 21 (1945a) 111-126 (recopilado en Álvarez de Miranda 1959a, 5-27).

— «Arte y política», Revista de estudios políticos 24 (1945b) 1-44 (recopilado en Álvarez de Miranda 1959a, 31-77).

— «La tragedia griega y los problemas de su utilización dramática moderna», Revista Nacional de Educación 53 (1945c) 27-37.

— «Prólogo» a L. Gillet, La catedral viva (traducción de J. García Mercadal), Madrid, Ediciones y Publicaciones Españolas S.A. (colección Sol y Luna), 1946, VIII-XXIV (recopilado en Álvarez de Miranda 1959a, 81-97).

— «Hacia un arte religioso», Alférez 1 (1947) 2-3 (reeditado en Estudios -Santiago de Chile172 (1947) 3-9 y recopilado en Álvarez de Miranda 1959a, 101-109).

— «Breviario del Quijote», Cuadernos Hispanoamericanos 1 (1948a) 362-364.

— «La civilización, el pecado y nosotros», Finisterre 35 (1948b) 269-273 (recopilado en Álvarez de Miranda 1959b, 5-10).

\footnotetext{
188 Álvarez de Miranda 1961, 16-17 y 22 nota 30. Cita en otras dos ocasiones en este libro a van der Leeuw, pero en temas más circunstanciales, en relación con los dioses gentilicios (46 nota 6) y en relación con el papel central del rey (47 nota 12$)$.

189 Como se expone en la nota 20.
} 
- «El mesianismo en el mito, la revelación y la política», Cuadernos Hispanoamericanos 2 (1948c) 349-352.

- Platón, Fedón (Introducción, texto y notas de Ángel Álvarez de Miranda), Madrid, Instituto «Antonio de Nebrija» del CSIC, 1948d (la introducción se ha recopilado en Álvarez de Miranda 1959a, 183-223 y en Álvarez de Miranda 2008, 53-78).

— «Los pueblos de España», Cuadernos Hispanoamericanos 3 (1948e) 588-591.

— «Picasso antes de Picasso», Cuadernos Hispanoamericanos 3 (1948f) 599-603.

— «Temas del Barroco», Cuadernos Hispanoamericanos 3 (1948g) 607-610.

— «Recensión de una actitud: Pedro Laín», Alférez 17 (1948h) 3 (recopilado en Álvarez de Miranda 1959a, 165-169).

- «En torno a una visión de España desde el exilio», Cuadernos Hispanoamericanos 4 (1948i) 89-95.

— «Las profecías se cumplen», Cuadernos Hispanoamericanos 4 (1948j), 210-212.

- Perfil cultural de Hispanoamérica, Madrid, Ediciones Cultura Hispánica (colección Santo y Seña), 1950a, 105 pp. (recopilado en Álvarez de Miranda 1959a, 243-305 y Álvarez de Miranda 2008, 121-161).

- «El pensamiento de Unamuno sobre Hispanoamérica», Cuadernos Hispanoamericanos 13 (1950b) 51-78 (recopilado en Álvarez de Miranda 1959a, 309-348)

— «Italia ante el problema de las relaciones culturales», Arbor 15/51 (1950c) 389-397.

— «Perspectiva del modernismo español», fechado en Roma en la primavera de 1951 (recopilado en Álvarez de Miranda 1959a, 351-375).

— «L'origine magica delle "corridas" nella Penisola Iberica ed in Creta con un appendice sulla magia sessuale del toro in alcuni miti e riti delle religioni antiche». Inédito. Tesis de laurea, Universidad de Roma, 1952a, 235 pp. (ejemplar conservado en el Archivo Pettazzoni, recopilada, con correcciones del italiano, en Nappo 2012, 7-152).

— «Miti e riti sulla sacralità del toro (contributo allo studio sull'origine e sviluppo dei suoi valori magico-religiosi)». Porta el encabezado: tesi di laurea che presenta l'allievo Alvarez de Miranda (Angelo) per ottenere il titolo di dottore in Scienze Storico-Religiose nella Facoltà de Lettere dell'Università di Roma. Inédito, 1952b (ejemplar presentado a la oposición de la cátedra de Historia de las Religiones de la Universidad de Madrid, custodiado en el Archivo General de la Administración, fondo del Ministerio de Educación, legajo 15.122 (top. 32/47-48 (05)001.009)), paginación discontinua, 201 pp.

- «Experiencia de un Instituto cultural español en el extranjero» (informe inédito mecanografiado sin fecha, 1952c (ejemplar en el archivo de los herederos de Ángel Álvarez de Miranda)

— «Magia y medicina popular en el mundo clásico y en la Península Ibérica», Archivos iberoamericanos de historia de la medicina 5/2 (1953a) 309-326 (recopilado en Álvarez de Miranda 1959b, 13-39).

— «Poesía y religión»: fechado en Roma, estío de 1953b, 68 pp. (recopilado en Álvarez de Miranda 1959b, 43-111 y publicado como monografía en Álvarez de Miranda 1963; 2010).

— «Poesía y religión», Revista de ideas estéticas 43 (1953c) 221-251 (publicación parcial de Álvarez de Miranda 1953b).

— «Urgencia de la etnología en la Universidad», Revista de Educación V/14 (1953d) 219222.

— «Anécdota sobre Ortega y la mitología», Revista 84 (1953e) 7 (recopilado en Álvarez de Miranda 1959a, 379-383).

— «Las religiones mistéricas y el problema de su inserción en la historia general de las religiones», trabajo científico para tomar parte en la oposición a la cátedra de Historia de las 
Religiones, preámbulo fechado en octubre de 1953f, 212 pp. (publicado como Álvarez de Miranda 1961).

- «Concepto de la historia en Polibio. El conflicto entre racionalismo y religiosidad y su proyección en la actitud ética e historiográfica de Polibio», Tesis doctoral inédita leída en la Universidad de Madrid, 1953g, 2 vols.

— «El sacerdote en la novela, o la nivelación de lo sagrado», Revista 88 (1953h) 7 (recopilado en Álvarez de Miranda 1959a, 387-392).

— «Magia y religión del toro norteafricano», Archivo Español de Arqueología, 27 (1954a) 3-45 (recopilado en Álvarez de Miranda 1959b, 115-178).

— «Job y Prometeo, o religión e irreligión», Anthologica Annua 2 (1954b) 207-237 (recopilado en Álvarez de Miranda 1959b, 235-285 y Álvarez de Miranda 2008, 21-51).

- «Sociología religiosa del marianismo Hispánico», Cuadernos Hispanoamericanos 54 (1954c) 253-264 (recopilado en Álvarez de Miranda 1959b, 213-232).

- «Cuestiones de mitología peninsular ibérica», Revista de la Universidad de Madrid III/9 (1954d) 25-43 (recopilado en Álvarez de Miranda 1959b, 181-210 y Álvarez de Miranda 2008, 81-100).

- El saber histórico-religioso y la ciencia española. Primera lección dada en la cátedra de «Historia de las religiones», Madrid, Universidad de Madrid, 1955a, 38 pp. (recopilado en Álvarez de Miranda 1959b, 289-315 y Álvarez de Miranda 2008, 1-18).

— «Reflexiones sobre lo telúrico», Cuadernos Hispanoamericanos 61 (1955b) 37-49 (recopilado en Álvarez de Miranda 1959a, pp. 435-456).

— «Un tratado de Historia de las Religiones», Cuadernos Hispanoamericanos 61 (1955c) 109-112.

- «Una interpretación histórica de nuestro tiempo», Cuadernos Hispanoamericanos 62 (1955d), 241-245.

— «Un nuevo libro de José Luis Aranguren», Cuadernos Hispanoamericanos 62 (1955e) 259-261.

— «Carácter de las religiones de Méjico y Centroamérica», Cuadernos Hispanoamericanos 65 (1955f) 167-184 (recopilado en Álvarez de Miranda 1959b, 319-347 y Álvarez de Miranda 2008, 163-181).

— «Reseña a Wilhelm Schmidt, Der Ursprung der Gottesidee», Arbor 31 (1955g) 171-174.

— «El padre Wilhelm Schmidt, España y la etnología», Arbor 32 (1955h) 275-287 (recopilado en Álvarez de Miranda 1959b, 351-372).

— «La irreligiosidad de Polibio», Emerita 24 (1956) 27-65 (recopilado en Álvarez de Miranda 1959b, pp. 381-431 y Álvarez de Miranda 2008, pp. 183-215, redactado en 1954).

- Obras I (Varia), (con prólogo de Joaquín Ruiz-Giménez) Madrid, Ediciones Cultura Hispánica (recopilación por Consuelo de la Gándara), 1969a, 471 pp.

- Obras II (Ensayos histórico-religiosos), (con prólogo de Pedro Laín Entralgo y epílogo de José Luis López Aranguren) Madrid, Ediciones Cultura Hispánica (recopilación por Consuelo de la Gándara), 1959b, 455 pp.

- Religiones mistéricas (con prólogo de Pedro Laín Entralgo), Madrid, Revista de Occidente, 1961, 244 pp.

- Ritos y Juegos del toro (con prólogo de Julio Caro Baroja), Madrid, Taurus, 1962, 218 pp.

- La metáfora y el mito, Madrid, Taurus, 1963, 72 pp.

- Ritos y Juegos del toro (con una nota preliminar de Pedro Álvarez de Miranda, nueva edición de Álvarez de Miranda 1962), Madrid, Biblioteca Nueva, 1998, 152 pp.

- Le taureau. Rites et jeux, Portet-sur-Garonne, Éditions Loubatières (traducción por Henrique Sopena de Álvarez de Miranda 1962), 2003, 159 pp. 
- Mito, religión y cultura, Anthropos, Barcelona (presentación, final y edición a cargo de Andrés Ortiz-Osés), 2008.

- La metáfora y el mito. Intuiciones de la religiosidad primitiva en la obra de Lorca, edición al cuidado de Pedro Álvarez de Miranda (con una presentación de 10 páginas), reedición corregida de Álvarez de Miranda 1963, Renacimiento, Sevilla, 2010, 137 pp.

- Ritos y Juegos del toro (con prólogos de Julio Caro Baroja y Consuelo de la Gándara y epílogo de Francisco Díez de Velasco), Sevilla, Athenaica, 2015, 308 pp.

J. L. L. Aranguren, Catolicismo y protestantismo como formas de existencia, Madrid, Revista de Occidente, 1952 (recopilado en Obras completas, vol. I, Madrid, Trotta, 1994).

- El protestantismo y la moral, Madrid, Ediciones Sapientia, 1954 (recopilado en Obras completas, vol. II, Madrid, Trotta, 1994).

— «Ángel Álvarez de Miranda y su vocación», Papeles de Son Armadans VI/XVIII (1957) 289-295 (retomado como «Epílogo» en Álvarez de Miranda 1959b, 435-441).

J. Caro Baroja, «Prólogo», en Álvarez de Miranda 1962, 7-9; 1998, 11-13; 2015, 6-8.

C. Castro Cubells, Memorias, manuscrito inédito (mecanografiado), sin fecha (escrito entre 1967 y 1997), 358pp.

G. Casadio, Lo sciamanesimo. Prima e dopo Mircea Eliade, Roma, Il Calamo, 2014.

O. Díaz Hernández, «Las revistas culturales en la España de la posguerra (1939-1951): una aproximación», Cuadernos del Instituto Antonio de Nebrija 10 (2007) 201-224.

F. Díez de Velasco, Ángel Álvarez de Miranda, historiador de las religiones, Madrid, ediciones del Orto, 2007a.

— «Ángel Álvarez de Miranda y la cátedra de Historia de las Religiones de la Universidad de Madrid: un proyecto truncado», Bandue. Revista de la Sociedad Española de Ciencias de las Religiones I (2007b) 83-133.

- «Eugenio d'Ors y Mircea Eliade», Archaeus, Studies in the History of Religions XIII (2009) 227-279 (refunde y aumenta «Mircea Eliade y Eugenio d'Ors (y el arquetipo)», 'Ilu 12 (2007) 59-81 y «Mircea Eliade y Eugenio d'Ors: notas sobre su correspondencia», 'Ilu 13 (2008) 55-70).

— «La Historia de los Heterodoxos, Menéndez Pelayo y la Historia de las Religiones (con un excursus sobre el budismo)» en Ramón Teja y Silvia Acerbi (dirs.), Historia de los Heterodoxos Españoles. Estudios, Santander, Publican/Sociedad Menéndez Pelayo, 2012, 53-75.

- Ritos y juegos del toro en la trayectoria investigadora de Ángel Álvarez de Miranda, Sevilla, Athenaica, 2015.

— «Escribir un manual de Historia de las Religiones en España, hoy: razones y retos», Historia Religionum. An International Journal 8 (2016) 133-143.

- «Los fallidos intentos de institucionalización de los estudios de historia de las religiones en la universidad española antes del franquismo: algunos hitos», en Germán Santana Henríquez y L.M. Pino Campos (eds.), Paideia kai Zetesis. Homenaje a Marcos Martínez, Madrid, Ediciones Clásicas, 2017a, 227-234.

- «Canarias en la reivindicación por parte de Ángel Álvarez de Miranda del papel de lo hispano en la historia general de las religiones», en AA.VV., Homenaje a Antonio Tejera Gaspar, La Laguna, 2017b, en prensa.

F. Díez de Velasco y P. Álvarez de Miranda, «El profesor Ángel Álvarez de Miranda: la Historia de las Religiones y el Instituto Español de Lengua y Literatura en Roma», en R. Olmos y otros (eds.), Repensar la Escuela del CSIC en Roma. Cien años de memoria, Madrid, CSIC, 2010, 551-563.

L. Duch, Antropologia de la religió, Barcelona, Publicacions de l'abadia de Montserrat, 1997. 
A. Duplá, «Santiago Montero Díaz. Un itinerario historiográfico singular», en Santiago Montero Díaz, De Caliclés a Trajano, Pamplona, Urgoiti editores, 2004, VII-XC.

M. Eliade, Tratado de historia de las religiones (traducción de Asunción Madinaveitia), Madrid, Instituto de Estudios Políticos (Biblioteca de Cuestiones Actuales, dirigida por Xavier Zubiri), 1954.

- Fragments d'un journal I (1945-1969) (traducción de Luc Badesco), Paris, Gallimard, 1973.

- Mémoire II (1937-1960). Les moissons du solstice (traducción de Alain Paruit), Paris, Gallimard, 1988.

- Diario 1945-1969 (traducción de J. Garrigós), Barcelona, Kairós, 2001a (hay otra traducción Fragmentos de un diario, Madrid, Espasa Calpe, 1979, por Isabel Pérez-Villanueva).

- Diario Portugués (traducción española de J. Garrigós), Barcelona, Kairós, 2001b.

- Jurnal 1941-1969 (texto rumano establecido por Mircea Handoca), Bucarest, Humanitas, 2004,

- Jurnalul Portughez si alte scrieri (texto rumano establecido por Florin Turcanu), Bucarest, Humanitas, 2006 (2 vols.), vol. 1, pp. 93-383.

M. Eliade y R. Pettazzoni, L'histoire des religions a-t-elle un sens? Correspondance 19261959 (edición establecida por N. Spineto), Paris, Cerf, 1994.

M. Gandini, «Raffaele Pettazzoni negli anni 1949-1950. Materiali per una biografia», Strada Maestra 60 (2006a) 20-237.

— «Raffaele Pettazzoni intorno al 1951. Materiali per una biografia», Strada Maestra 61 (2006b) 56-246 (incluye el subcapítulo «L'allievo Ángel Álvarez de Miranda (intorno al 1950)»: 117-118).

— «Raffaele Pettazzoni negli anni 1952-1953. Materiali per una biografia», Strada Maestra 62 (2007a) 2-191.

— «Raffaele Pettazzoni negli anni 1954-1955. Materiali per una biografia», Strada Maestra 63 (2007b) 2-241.

— «Raffaele Pettazzoni (1883-1959). Materiali per una biografia. Indice generale - Indice dei nomi di persona. Bibliografia degli scritti», Strada Maestra 66 (2009) 1-255.

J. Guitton, La Virgen María, Madrid, Rialp (colección Patmos), 1952 (traducción de Alberto Pérez Masegosa y prólogo de Raimundo Paniker) (original, París, Aubier, 1949).

C.G. Jung, «Picasso», en C.G. Jung, Obra completa, vol. 15: Sobre el fenómeno del espíritu en el arte y la ciencia, Madrid, Trotta, 1999 (or. 1932), 125-130.

A. Lago Carballo, «Crónica y repaso de la revista Alférez», en J. L. García Delgado (ed.), Economía española, cultura y sociedad. Homenaje a Juan Velarde Fuertes ofrecido por la Universidad Complutense, Madrid, EUDEMA, 1992, vol. III, 489-510.

— «Álvarez De Miranda Vicuña, Ángel», en Diccionario Biográfico Español, Madrid, Real Academia de la Historia, vol. III (2009), 602-603.

P. Laín Entralgo, «Poesía, ciencia y realidad», Cuadernos Hispanoamericanos 31 (1952) 13-30 (recopilado en Palabras menores, Barcelona, editorial Barna, 1952, 1-23).

— «Prólogo», en Álvarez de Miranda 1959b, IX-XVIII (retomado en Más de cien españoles, Barcelona, Planeta, 1981, 312-315).

— «Prólogo», en Álvarez de Miranda 1961, IX-X.

J. Maritain, Tres reformadores, Madrid, EPESA, 1948 (traducción de Ángel Álvarez de Miranda) (nueva edición Tres reformadores (Lutero, Descartes, Rousseau), Madrid, Encuentro, 2006).

S. Montero Díaz, «Estoicismo e historiografía», Revista de la Universidad de Madrid III/1 (1943) 67-89. 
— «El mito de Quetzalcóatl», Cuadernos Hispanoamericanos 15 (1950) 441-456.

- De Caliclés a Trajano, Pamplona, Urgoiti editores, 2004 (ed. original: Madrid, Instituto de Estudios Políticos, 1948).

S. Montero Herrero, «Publicaciones del Profesor Santiago Montero Díaz», Gerión anejo II (1989) 15-21.

J. Muñoz Soro, «Joaquín Ruiz-Giménez o el católico total (apuntes para una biografía política e intelectual hasta 1963)», Pasado y Memoria. Revista de Historia Contemporánea 5 (2006) 259-288.

M. A. Nappo, «Corrida e Storia delle religioni nell'opera di Angel Alvarez de Miranda», Tesis de laurea (inédita), Universidad de Salerno, 2012.

E. d'Ors, Du baroque (traducción de Agathe Rouart-Valéry, NRF, Gallimard, París, 1935.

- Lo barroco, Aguilar, Madrid, 1944.

— «Sacramento, 1. Don Eugenio se ha traído de Italia un ángel napolitano. Importante labor cultural de España: Entrevista con Rafael García Serrano», Arriba, 8 de julio de 1949a.

— «Estilo y Cifra. España fuera de España», La Vanguardia española, 5 de julio de 1949b.

- «Entrevista con D. Eugenio D’Ors a su regreso de Roma. La labor del Instituto Español de Lengua y Literatura, por J. F. Vila San-Juan», La Vanguardia española, 6 de julio de 1949c.

— «Estilo y Cifra. Espejo de cronistas», La Vanguardia española, 7 de mayo de 1954a.

— «Perspectivas académicas», Arriba, 8 de julio de 1954b.

A. Ortiz-Osés, «Mitología hispánica: Ángel Álvarez de Miranda», 'Ilu 5 (2000) 119-123 (recopilado como «Presentación. Mitología hispánica», en Álvarez de Miranda 2008, IX-XIV).

— «Final. Mitología de la cultura», en Álvarez de Miranda 2008, 217-223.

F. Pérez Embid, Las revistas culturales de postguerra, Madrid, Publicaciones Españolas, 1954.

R. Pettazzoni, Le origini dei Kabiri nelle isole del mar Tracio, Roma, Accademia del Lincei, XII, 1908.

- La religione di Zarathustra nella storia religiosa dell'Iran, Bologna, Zanichelli, 1920.

- Dio. Formazione e sviluppo del monoteismo nella storia delle religioni, vol. I: L'essere celeste nelle credenze dei popoli primitivi, Roma, Athenaeum, 1922.

- I misteri. Saggio di una teoria storico-religiosa, Bologna, Zanichelli, 1924.

- La confessione dei peccati, I Primitivi-America antica-Giappone-Cina-BrahmanesimoGiainismo-Buddhismo, Bologna, Zanichelli, 1929.

- La Confession des Péchés. I. Primitifs-Amérique ancienne, Paris, Ernest Leroux, 1931a.

- «Die Nationalreligion Japans und die Religionspolitik des japanischen Staates», Orient und Occident (Blätter für Theologie und Soziologie) 5 (1931b) 33-47.

- La confessione dei peccati, II/3 Siria, Hittiti, Asia Minore, Grecia, Bologna, Zanichelli, 1936.

— «A functional View of Religions», The Review of Religion 1 (1936-37) 225-237.

- «La religione», en Augustus. Studi in occasione del Bimillenario Augusteo, Roma, Accademia dei Lincei, 1938, 217-249.

- Saggi di storia delle religioni e di mitologia, Roma, Edizioni Italiane, 1946.

- Miti e leggende. I. Africa. Australia, Torino, Unione Tipografico-Editrice Torinese, 1948.

- Nozioni di mitologia (texto recogido por Ernesta Cerulli y A. Becattini), Roma, Perella, 1949.

- Italia religiosa, Bari, Laterza, 1952a.

— «Un congresso "non opportuno"», Il Mondo 3/153 (19 de enero) (1953b) 4 (recopilado en Religione e società, a cura di Mario Gandini, Bologna, Editrice Ponte Novo, 1966, 155-159). 
- La religione nella Grecia antica fino ad Alessandro, Torino, Einaudi, 1953.

- Le religioni misteriche nel mondo antico (texto recogido por Angelo Brelich), Roma, Perella, 1953.

J. Ruiz-Giménez, «Prólogo: diálogo con Ángel», en Álvarez de Miranda 1959a, VII-XVIII (recopilado en Del Ser de España, Madrid, Aguilar, 1963, 263-272).

W. Schmidt, Manual de historia comparada de las religiones. Origen y formación de la religión, teoría y hechos, Madrid, Espasa Calpe, 1932.

Sin autor, Obras ingresadas. Donación Ángel Álvarez de Miranda, folleto, Biblioteca de la Facultad de Geografía e Historia de la Universidad Complutense, 1987, 25 pp.

N. Spineto, Mircea Eliade storico delle religioni, Brescia, Morcelliana, 2006.

- «Raffaele Pettazzoni, Mircea Eliade e il dibattito fra storicismo e fenomenologia. Un inedito di Ugo Bianchi» en C. Giuffrè y A. Mastrocinque, Ex pluribus unum. Studi in onore di Giulia Sfameni Gasparro, Roma, Quasar, 2015, 485-496.

F. Turcanu, Mircea Eliade. Le prisonnier de l'histoire, Paris, La Découverte, 2003.

R. Valdés, «Mis maestros» 2006, http://revista-redes.rediris.es/recerca/rvaldes/Mis\%20maes tros.pdf [acceso 05.03.2017].

J. M. Velloso, «Corresponsal en Roma», en AA.VV., Dionisio Ridruejo, de la Falange a la oposición, Madrid, Taurus, 1976, 111-118.

X. Zubiri, Naturaleza, Historia, Dios, Madrid, Editora Nacional, 1944 (2ª ed. 1951). 